\section{The Global Positioning System Geodesy Odyssey}

\author{
Alan G. Evans, ${ }^{(1)}$ ed.; Robert W. Hill, ${ }^{(2)}$ ed.; \\ Geoffrey Blewitt; ${ }^{(3)}$ Everett R. Swift; ${ }^{(1)}$ \\ Thomas P. Yunck; ${ }^{(4)}$ Ron Hatch; ${ }^{(5)}$ \\ Stephen M. Lichten; ${ }^{(4)}$ Stephen Malys; ${ }^{(6)}$ \\ John Bossler; ${ }^{(7)}$ and James P. Cunningham ${ }^{(1)}$
}

1. Naval Surface Warfare Center, Dahlgren Division, Dahlgren, Virginia

2. Applied Research Laboratories, University of Texas, Austin, Texas

3. Nevada Bureau of Mines and Geology, and Seismological Laboratory, University of Nevada, Reno, Nevada

4. Jet Propulsion Laboratory, California Institute of Technology, Pasadena, California

5. NAVCOM Technology, Inc., Redondo Beach, California

6. National Imagery and Mapping Agency, Bethesda, Maryland

7. Center for Mapping, The Ohio State University, Columbus, Ohio

\begin{abstract}
Fundamental to NAVSTAR Global Positioning System (GPS) operation and application are the computational developments that have led to accurate user positioning. This paper discusses some of these developments from a historical perspective. The developmental odyssey begins with the events leading to initial GPS operation. Early developments in satellite geodesy, which led to the GPS constellation development, are briefly reviewed. A chronology of the incremental improvements in satellite orbit determination is presented. Contributions basic to GPS operation and accuracy, including coordinate frame definition and software development for user absolute and differential/kinematic positioning, are reviewed. Applications-including surveying and mapping, geodynamics, and spaceborne geodesy, which have motivated the most stringent accuracy requirements for GPS-are discussed. The paper ends with a discussion of expected future geodetic capabilities and then a summary of the impact of GPS geodesy contributions to the user community.
\end{abstract}

\section{INTRODUCTION}

Geodesy and GPS have had a synergistic relationship that began well before the first GPS satellite was launched. Indeed, the roots of this relationship began before the first man-made satellite was orbited.

Geodesy is the science concerned with the accurate positioning of points on the surface of the earth, and the determination of the size and shape of the earth. It includes studying and determining variations in the earth's gravity, and applying these variations to exact measurements on the earth [1]. Prior to the advent of satellite geodesy, geodesists (and certainly navigators of that era) concerned with measuring and mapping the earth's surface usually conducted their analysis in two surface dimensions rather than the three space dimensions. Altitude above the surface was included but treated separately from horizontal positions. This does not mean the geodesists considered the earth to be flat; on the contrary, usually points are projected onto a curved reference surface or ellipsoid. The third dimension of height above the reference surface, while small when compared to the earth's radius, could be projected approximately onto the surface with acceptably small errors for short measurement baselines. However, as measurement baselines became longer through stellar and, more recently, satellite observations, it has become simpler to obtain acceptably small projection errors by considering the lines of observation in three dimensions, and by performing computations and network adjustments in three dimensions [2].

Satellite geodesy can be considered to have motivated three-dimensional geodesy. In a proposal dated 13 April 1955, scientists at the Naval Research Laboratory (NRL) proposed a scientific satellite program that included, as one of its major items, the application of satellite observations to the "field of geodesy" [3]. In the proposal, the discrepancies among reference ellipsoidal parameters, the problem of not knowing the semimajor axis of the earth to better than $300 \mathrm{~m}$, and the procedures for determining the absolute positions of ground station locations were detailed. The paper set the stage for satellite geodesy, outlining both classic triangulation and what came to be known as dynamic satellite geodesy.

Soon after the first satellites were in orbit, geodesists, by observing the perturbing effect on satellite motion, began to evaluate the earth's gravitational field [4-6]. These determinations were followed by a rapid succession of more extensive and accurate descriptions of the earth's gravity field. Early space geodesy was conducted primarily using optical instruments (photographic processes) adapted from earlier stellar systems. With the development of the Navy Navigation Satellite System (TRANSIT) 
[7], Doppler satellite geodesy became a cheaper, more rapid technique for space geodesy.

One of the striking characteristics of space geodesy in the 1960s and 1970s was the almost complete separation between the optical school and the Doppler school. By 1965 a global gravity field (NWL 5E), comprising about 70 coefficients, had been determined using Doppler satellite data [8]. Interestingly, the measured coordinates of ground stations agreed with a precise survey to about $20 \mathrm{~m}$, while distances between stations agreed with precise survey to about $10 \mathrm{~m}$, leading the U.S. DoD to adopt the Doppler system as its primary space geodesy system. Subsequent DoD World Geodetic Systems (WGS) were heavily influenced by Doppler satellite geodesy. The World Geodetic System 1972

(WGS 72), considered to be the standard for about a decade, contained a gravity field represented by about 450 coefficients and could demonstrate a system consistency of about $1 \mathrm{~m}$, while the overall accuracy for tracking station locations was estimated at about $3 \mathrm{~m}$. In the WGS 84, several thousand gravity coefficients were determined, and the separation between "Optical" and "Doppler" satellite measurements was somewhat reduced; however, most major datum parameters were greatly influenced by Doppler satellite measurements. Space geodesy computations performed with WGS 84 demonstrate internal consistency of several tens of centimeters, with an estimated accuracy of about $1 \mathrm{~m}$.

The 1980s were transition years for space geodesy in that they represented the maximum use and accuracy of Doppler satellite techniques. Investigators routinely reported submeter accuracy for Doppler surveys [9] and a few tens of centimeters for network adjustments. By the end of the decade, many geodesists had made the transition to GPS.

The accuracy for dynamic geodesy and-to a large extent-all space geodesy, is dependent on accurate positioning of the satellite. In turn, satellite orbit computation accuracy (and satellite ephemeris accuracy) is dependent on the accuracy of the space geodesy. Satellite observations made from the ground can be used accurately only if the ground station locations are known accurately, while the orbit itself can be computed accurately only if all of the forces governing the satellite motion are known. The early dynamic geodesists observed satellite prediction errors and made bootstrap corrections to the gravity models. GPS benefited greatly from the existing WGS gravity model. Techniques that eliminate common-mode errors among ground locations provide improved accuracy over limited distances, but they still depend on satellite position accuracy. GPS geodesy, like GPS navigation, relies on the accuracy, quality, and timeliness of the orbit computation and prediction.

Final introductory comments need to be made with regard to GPS tracking equipment and receivers. As noted previously, GPS geodesy is synergistically dependent on accurate satellite ephemerides; everything fails if the GPS receiver does not provide accurate measurements. Fortunately for geodesy, the GPS signal structure allows for very accurate measurements, positions, and times to be obtained. For more information on GPS signal structure, see [10, 11]. Precision ephemerides for GPS have been computed using three generations of ground receivers. The precise ephemeris was and is computed combining data from the GPS operational tracking stations and the Defense Mapping Agency (DMA)—since October 1996 the National Imagery and Mapping Agency (NIMA) - tracking network. The first-generation receiver, termed the NAVSTAR Geodetic Receiver System (NGRS), was based on a Stanford Telecommunications model 5007 receiver. Of particular interest was the full-cycle counter, which greatly enhanced the ability to measure accurately integrated Doppler phase counts over long (60 s) time intervals. The STI 5007 receiver was designed to measure range on the $\mathrm{L} 1$ frequency $(1575.42 \mathrm{MHz})$ with a precision of $1 \mathrm{~m}$. Its most important feature was its capability to measure phase counts on L1 and L2 (1227.6 MHz) with a precision of 0.025 cycles, while tracking both frequencies on a single satellite simultaneously $[12,13]$. The second generation of receiver was based on the Texas Instruments model TI4100. The TI4100 proved to be an extremely capable receiver system and for many years was used as a yardstick for judging less capable receivers. The TI4100-based trackers multiplexed the tracking channels to provide simultaneous range and integrated range rate on both L-band GPS frequencies for up to four satellites [14]. Significantly for geodesy, the pseudorange and integrated phase measurements were synchronized to occur at specified GPS times. The third-generation GPS receivers used at the DMA monitor stations were based on the Ashtech Z/Y-12. In late 1994, the DMA Monitor stations were upgraded by the $\mathrm{Z} / \mathrm{Y}-12$. These new DMA monitor stations have proven to be accurate and reliable in tracking the GPS satellites, and provide range and phase measurements on both frequencies for up to 12 satellites in view [15]. Additional geodetic receiver developments are discussed later in the paper.

Webster defines odyssey as "a long wandering usually marked by many changes of fortune." In reviewing the following geodetic journey, readers must evaluate its changes for themselves. However, the goal of the geodetic community has been focused and clear. The objective has continually been the im- 
proved accuracy of GPS satellite orbit determination, user positioning, and earth modeling. This paper reviews developments in these areas to help provide a background and understanding of the geodetic aspects of GPS.

\section{ORBIT DETERMINATION}

Early estimation of GPS satellite orbits and clock states was performed using a two-stage process in the operational production of the broadcast navigation message. The early work was transitioned into the GPS Operational Control System for real-time operations and into precise orbit determination (POD) for meeting the high-accuracy goals of the geodetic community. The following sections review these developments, including the corresponding reference frame definitions and the positioning of GPS tracking sites.

\section{INITIAL OPERATION}

Estimating and predicting GPS satellite orbit and clock states in near real time and uploading the navigation message information broadcast by the satellites has always been the responsibility of the U.S. Air Force (USAF). This began with the launch of the first Block I satellite in 1978. At that time, the USAF had deployed a four-station North Pacific basintracking network using Magnavox-developed fourchannel X-set receivers. This Initial Control System (ICS), developed by the General Dynamics Corporation, consisted of four monitor stations located in Hawaii, Guam, and Alaska; and a Master Control Station (MCS) with a single-upload antenna located at Vandenberg Air Force Base in California. With this four-station network, each Block I satellite could be tracked only about $50 \%$ of the time. The ICS was optimized for validating the GPS navigation concept and testing user equipment under development at the Yuma Proving Ground in Arizona and at other western continental United States (CONUS) locations. The original Block I constellation was designed so that the satellites would cluster over the western CONUS once per day. The satellites could be tracked for several hours and then uploaded prior to their coming into view at Yuma.

The Naval Surface Warfare Center, Dahlgren Division (NSWCDD) supported the ICS by producing long-term orbit predictions and partial derivatives that were used as reference trajectories in a Kalman filter run at the MCS [16]. This was initially conducted on a weekly basis and was eventually performed every other week. The WGS 72 gravity field model truncated to degree and order 8 and the Rockwell-formulated radiation pressure model [17] were both used in integrating the equations of motion for each satellite. Weekly batch least-squares orbit fits were first performed using 15-min smoothed pseudorange data, with clock parameters estimated on a pass-by-pass basis. The accuracy of these weekly fits was improved when a procedure was implemented in which successive pseudorange measurements were differenced to obtain range difference measurements. This time differencing removed the effects of clock jumps and allowed better modeling of the remaining stochastic clock effects. The MCS Kalman filter used the smoothed pseudorange measurements directly because it included stochastic models for the clocks and had to predict satellite clock states in addition to the orbits.

In the early years of GPS orbit estimation and prediction, satellite-momentum dump thrusts caused considerable problems. Initial fit errors were on the order of $20 \mathrm{~m}$ and initial orbit prediction error growth rates were on the order of $100 \mathrm{~m} /$ day [18]. The orbit fitting and predicting errors were reduced in the early 1980s after a means was developed for dumping momentum magnetically. In about 1980, after analysis led by personnel at the Aerospace Corporation, the "y-bias" acceleration parameter was introduced into the fitting, predicting, and Kalman filtering procedures. The y-bias is an empirical parameter used to model accelerations of unknown cause along the solar panel axis. Orbit prediction error growth rates were reduced to less than $10 \mathrm{~m} /$ day. Estimation of this y-bias parameter by the ICS dramatically improved the quality of the broadcast navigation messages. When the ICS was decommissioned in 1985, the broadcast user range error (URE) accuracy was better than $5 \mathrm{~m} 1 \sigma$ [19].

\section{OPERATIONAL CONTROL SEGMENT (OCS)}

The OCS-developed by International Business Machines/Federal Systems (now part of Lockheed Martin Management and Data Systems) - began control of the Block I satellites in July 1985. The OCS consists of five globally distributed tracking sites in Colorado Springs, Ascension Island, Diego Garcia, Kwajalein, and Hawaii; three upload antennas collocated at Ascension, Diego Garcia, and Kwajalein, and an MCS at Colorado Springs. With these five stations, each satellite can be tracked over $80 \%$ of the time. A complete description of the OCS is contained in [20]. A requirement was established for the OCS to provide a 1- $\sigma$ URE of less than $6 \mathrm{~m} 10 \mathrm{hr}$ after upload. Initial ICS vs. OCS comparisons indicated that this could easily be met $[19,21]$. The Kalman filter used by the OCS can process up to six satellites in a single partition and uses 15-min pseudorange measurements smoothed using carrier-phase data. Kalman filter estimates are used to generate 
Navigation, Journ. of the Inst. of Navigation, Vol. 49(1), 7-34, Spring 2002

new predicted reference trajectories on a weekly basis.

Orbit estimation and prediction accuracies have gradually improved over the years. A 30-day evaluation of OCS accuracy for Block I satellites was conducted in 1986 with UREs of 3 to 5 m estimated independently by several organizations [22]. The WGS 84 gravity field model replaced the WGS 72 model in 1987. The ROCK42 radiation pressure model was implemented for Block II satellite orbit estimation [23]. This model is still in use even though its limitations were discovered and evaluated in 1990 [24]. A discussion of the operational aspects of the OCS Kalman filter is given in [25]. An estimation procedure that eliminated the use of a master clock was implemented in June 1990 [26].

Another comprehensive study of UREs conducted in 1993 indicated a 3- to 4-m orbit accuracy [27]. In 1994 the OCS evaluated and updated the clock process noise statistics used for all satellites and stations [28]. The OCS continues to reevaluate and adjust these statistics on a routine basis. In early 1997, the OCS implemented an ephemeris enhancement endeavor. This involved updated orbit and radiation pressure/y-axis acceleration process noise levels [29]. This improved the orbit estimation and prediction accuracies further so that the broadcast UREs were in the 2.0- to 2.5-m range [30]. With six Block IIR satellites now operating, the broadcast UREs have been reduced to about $1.6 \mathrm{~m}$. The URE accuracies will continue to improve as more Block IIR satellites replace Block II/IIA satellites.

\section{Operational Initiatives}

The Space Segment is currently undertaking a modernization program leading to GPS upgrades for the replenishment satellites well into the $21^{\text {st }}$ century. These upgrades include (1) the addition of a new civil code signal on the L2 frequency (L2C) and the new military (M-code) signal on the L1 and L2 frequencies on the last 12 Block IIR satellites; (2) plans for similar upgrades to the Block IIF satellites, with the addition of a third GPS civil signal at $1176.45 \mathrm{MHz}$ (L5); and (3) planned GPS III satellites that are to have the above capabilities plus increased power for the M-code signals. The nominal schedule for an Initial Operational Capability (IOC) of 18-satellite earth coverage of the M-code and L2C code is 2008. The planned L2C IOC is 2012. The planned high-power M-code IOC is 2016 . The OCS will correspondingly be upgraded to support the modernization program. Further discussion on GPS modernization and its future expected performance is given in [31] and [32].

The USAF is also currently in the process of implementing a program called the Accuracy Improvement Initiative (AII), which will lead to further improvements in the quality of the broadcast navigation messages. This program [33] includes incorporating tracking data from six globally distributed NIMA stations, single-partition processing in the OCS Kalman filter, and a new upload strategy. With these improvements, the expected URE delivered to navigation users will be below $1.3 \mathrm{~m}$. Operational implementation of the AII changes is planned for late 2004 or early 2005.

\section{PRECISE ORBIT AND CLOCK ESTIMATION}

The fitted portions of the four-station-based reference trajectories generated for the ICS by NSWCDD were called "precise" ephemerides and were provided to organizations such as DMA, NRL, and others from 1980 through 1985. In 1981 experiments were begun on improving the quality of the precise orbits by including data from up to three additional tracking stations deployed by DMA to Australia, Seychelles, and Argentina [34, 35]. These stations used the early geodetic-quality receivers built by Stanford Telecommunications, Inc. All of these orbit fits were single-satellite solutions using time differences of pseudorange measurements from the USAF stations and integrated Doppler measurements from the DMA stations.

The quality of the precise ephemerides was improved in September 1985 when NSWCDD's next generation of estimation software, called OMNIS, replaced the batch fit software [36, 37]. It used data from the five OCS stations and three of the DMA stations. This software implemented a multisatellite Kalman filter/smoother estimation algorithm using the 15-min smoothed pseudorange data directly, since the stochastic nature of the satellite and station clocks could be accommodated as estimated states. Unmodeled accelerations acting on the satellites could also be accommodated. The multisatellite capability allowed better separation of the satellite and station clock variations from the orbits. By 1987, DMA had deployed second-generation, geodetic-quality TI4100 receivers to tracking sites in Australia, Argentina, England, Ecuador, and Bahrain. An evaluation conducted in 1987 indicated that radial orbit accuracy was probably at the 1-m level, with horizontal errors at the 3-m level per component [38]. Also, in 1987 evidence that the Block I clocks were undergoing large orbit period variations was believed to be due to thermal cycling on the satellites [39]. Changes to the clock estimation procedures were implemented at the beginning of 1988 to handle these variations. A solid-earth tide correction to station coordinates was also added at this time. All of the DMA stations were updated to dual TI4100 configurations by December 1989. 
In July 1989, production of the precise ephemerides for the Block I satellites was transitioned to DMA in Bethesda, Maryland. Improvements over the next few years included changes to the radiation pressure scale parameter designed to address estimate degradation during eclipse seasons [40]. Starting in 1991, plate motion effects on the station coordinates (using the AM0-2 model), and more accurate earth's orientation computation were incorporated [41].

In June 1993, production was moved from Bethesda to DMA facilities in St. Louis, Missouri. Ashtech Z-12 receivers replaced the T14100 receivers at the DMA stations by December 1993. In January 1994, more accurate station coordinates were introduced (see next subsection) and the NUVEL NNR-1 plate motion model was implemented [42]. During 1995, DMA deployed additional tracking stations at the U.S. Naval Observatory (USNO) in Washington, DC, and Beijing, China, bringing the total number of stations to 12 . In early 1995 , all Ashtech receivers were upgraded to be Y-code capable. Tracking station antennas were upgraded in August 1995 to reduce multipath effects.

With 12 stations in place, it was determined that interferometric-type processing could be implemented to take advantage of the precise carrier-phase data in addition to the smoothed pseudorange data. These data and the new processing approach were adopted by DMA in late September 1996 and modified in November to provide for better clock estimation. Further NSWCDD analysis and the addition of better tropospheric refraction modeling resulted in another set of changes being adopted by the NIMA in late November 1997. These two sets of changes resulted in RMS UREs associated with the NIMA precise ephemerides of better than $10 \mathrm{~cm}$ [43]. The recent addition of four more stations by NIMA has resulted in this URE being reduced to about $5 \mathrm{~cm}$.

\section{Coordinate Frame Definition: World Geodetic System}

The global reference frame currently used by DoD, the World Geodetic System 1984 (WGS 84), was defined by the DMA [44]. In addition to the improved reference frame, the development of the WGS 84 included estimating a refined geopotential (gravity) model and determining coordinates for satellite tracking stations. This section addresses the development and continuing refinement of the operational WGS 84 reference frame, defined presently by the coordinates of two DoD globally distributed networks of GPS tracking stations. One network consists of five USAF GPS tracking stations used in their real-time computations of the GPS broadcast ephemerides while the other station network is main- tained by NIMA and used, along with data from the USAF stations, in their precise orbit and clock estimation.

Geodetic systems, such as WGS 84, include a definition of the coordinate reference frame, parameters of the reference ellipsoid, and associated geodetic and geophysical constants. The process used in developing such systems produces self-consistency between the reference frame and the coordinates of the stations used in the process. At the time of the WGS 84 development, its reference frame realization was defined by TRANSIT tracking stations; however, to define the most accurate TRANSIT coordinates, external calibration was necessary. All radio frequency tracking systems (i.e., TRANSIT and GPS) have a nearly longitude-independent observation. Within these tracking systems, absolute determination of station longitude is ambiguous. External comparison and calibration is performed between sets of station coordinates to allow for uniform systematic station network adjustments.

In 1983 the WGS 84 development committee adopted the Bureau International de l'Heure Terrestrial System (BTS) as the external comparison standard for the WGS 84. The BTS, based on very long baseline interferometry (VLBI) and other observations, was globally distributed and very accurate. The WGS 84 TRANSIT tracking station coordinates were adjusted to match the BTS as well as possible.

The preliminary WGS 84 coordinates of the USAF and DMA GPS tracking stations were obtained by transformation from their WGS 72 coordinates. During 1985 and 1986, the WGS 84 coordinates were directly derived using Doppler TRANSIT pointpositioning by DMA. This positioning technique used the recently calibrated WGS 84 Doppler station coordinates, Doppler observations collected from TRANSIT satellites, and the WGS 84 gravity model. The WGS 84 positions of the GPS tracking stations were defined by transferring WGS 84 positions of nearby collocated Doppler stations using terrestrial survey differences [45].

Uncertainties in these Doppler-derived WGS 84 station coordinates were attributed principally to uncompensated ionospheric effects on signal propagation and, to a smaller extent, the determination of the electrical phase center of the antennas. TRANSIT, like GPS, used dual-frequency observations to correct for ionospheric effects. This correction's residual errors are inversely proportional to the satellitetransmitted frequencies. Ionospheric corrections for the TRANSIT low-frequency observations contained relatively large residual errors; these errors primarily corrupted the height of Doppler-derived coordinates. Smaller errors in the GPS station coordinates were introduced by inaccurate definitions of the electrical 
phase center of both the TRANSIT and GPS antennas used in the coordinate transfers. The combination of these and other errors made the initial GPS station coordinates internally inconsistent and biased with respect to the BTS. The largest bias, which was in the GPS station heights, was estimated to be at the meter level.

Once the initial WGS 84 GPS stations were defined, tracking station coordinates could be developed using GPS tracking data, and GPS precise clocks and orbits. However, successful redetermination of WGS 84 station coordinates within the GPS system would be a measure of only internal GPS consistency. External comparison and calibration would still be needed to assure the best absolute position accuracy.

The Doppler-realized coordinates, discussed above, were defined to be consistent with the BTS. Over time, the BTS has been refined to the International Terrestrial Reference Frame (ITRF) provided by the International Earth Rotation Service (IERS). To maintain consistency, the WGS 84 GPS station coordinates have been tied to the ITRF. New coordinates for the operational USAF and DMA tracking stations have been determined twice. Each set of coordinates showed improved accuracy over the previous set.

The first GPS derivation of WGS 84 coordinates used data collected in 1992 from the ten USAF and DMA stations and from a set of globally distributed civilian stations defined in the ITRF [46]. A subset of the ITRF stations, called fiducial sites, was held fixed, while simultaneously estimating GPS clocks, orbits, and the station coordinates of the USAF, DMA, and remaining ITRF sites. These WGS 84 coordinates of the DoD stations were improved over the Doppler-realized coordinates due primarily to elimination of the height bias (approximately $1.5 \mathrm{~m}$ in magnitude) and redefinition of longitude. The estimated $1-\sigma$ accuracy of these GPS-realized WGS 84 coordinates was $10 \mathrm{~cm}$ per component, an order of magnitude better than the accuracy of the Dopplerrealized coordinates. These WGS 84 (G730) coordinates were adopted by DoD in 1994.

The DoD coordinates were rederived in 1996 for the purpose of validation and also to improve the coordinates of two new DMA stations and two DMA stations relocated since the previous solution [47]. In this second GPS-based derivation, the DoD coordinate solutions were tied to the ITRF by again holding fixed the coordinates of the fiducial stations, while solving simultaneously for GPS clocks, orbits, and the station coordinates. The new DoD coordinates are now estimated to have an accuracy of better than $5 \mathrm{~cm}$ per component, $1 \sigma$. DoD adopted the improved WGS 84 (G873) coordinates.
Refinement of the WGS 84 reference frame continues, with future improvements to potentially yield station coordinates accurate to a centimeter, or better, per component of position. In addition, station velocities, used to propagate the station coordinates to different epochs, will be estimated; consequently, the small inaccuracies associated with using worldwide plate motion models will be eliminated.

\section{Earth Orientation Prediction and Estimation}

Earth orientation predictions for GPS have always been done on a weekly basis. For the ICS, NSWCDD performed the predictions based on USNO data [48] and the ICS updated these predictions in near real time using the tracking data from its four-station Pacific Basin network. With the implementation of OCS, the prediction task was moved to DMA [49]. The OCS does not estimate any earth orientation parameters but the inertial orbit planes can rotate to accommodate slowly changing UT1UTC errors, where UTC is the Coordinated Universal Time, and Universal Time 1 is a rotation about the pole representing the siderael rotation of the earth.

In computing the precise ephemerides, the earth orientation predictions generated by DMA/NIMA initially included constant offsets for the two pole coordinates and the UT1-UTC [50]. Starting in 1991, solid-earth zonal tide effects on UT1-UTC were added to the initial values, and pole coordinate rates and a UT1-UTC acceleration parameter were also estimated.

\section{POSITIONING}

\section{ABSOLUTE POSITIONING}

The term absolute positioning, when used in the discipline of geodetic surveying, generally refers to a process that establishes the earth-centered, earthfixed coordinates of a solitary station on the earth's surface. Unlike relative positioning (differential positioning), the absolute positioning process does not depend on use of a previously determined reference station position. Instead, a set of satellite positions and clock states are obtained from an existing satellite ephemeris. A position estimation algorithm is employed that uses data collected at the solitary station over some period of time, typically at least a few hours or more.

\section{Background}

While the commercial surveying community quickly developed and embraced the relativepositioning capabilities that GPS offered, virtually all commercial surveyors continue to rely on government agencies, such as the National Geodetic Survey, 
or similar agencies in other countries for absolute survey control points. The DoD relies on NIMA for absolute survey control, while research institutions generally create their own control or rely on results generated by other institutions in the international scientific community. For these reasons, a small number of geodetic organizations have concerned themselves with developing GPS geodetic absolute positioning capabilities. In the United States, these organizations include NIMA, NSWCDD, The University of Texas at Austin, and NASA's Jet Propulsion Laboratory (JPL). Outside of the United States, researchers at the University of Calgary and a few other research organizations have also developed algorithms and performed analysis in this area.

An application of absolute geodetic positioning is the estimation of geodetic datum transformations. When a set of geodetic control points, established in a local or regional horizontal geodetic datum, are positioned with an absolute GPS point-positioning technique, a set of similarity transformation parameters can be determined. These parameters can then be used to convert maps, charts, or other geospatial data from a local or regional datum into a global reference frame such as WGS 84. Conversely, a GPS user's navigation position can be converted from WGS 84 into a local or regional datum by application of these transformation parameters. NIMA maintains a large set of these transformations and makes them available for GPS receiver manufacturers and other users. They can be found in TR8350.2 [45] or on the World Wide Web at:

http://www.nima.mil/GandG/pubs.html.

Another application for geodetic point positions lies in establishing geodetic control networks, which are needed for a variety of purposes, including high resolution geoid modeling. Other applications, such as geodetic control of remotely sensed imagery and the metric evaluation of remotely sensed imagery, are particularly important within DoD since they support the targeting processes for a number of modern weapons systems. Other military applications of geodetic point positions are discussed in [51].

\section{Pseudorange Observation Equation: Relationship to Absolute Positioning}

The pseudorange observation is the link between the user and the satellites. It is instructive to decompose this observation into its various parts to establish where the sources of error lie. The observation is a measurement, determined by the receiver, of the time interval between the reception and transmission of an L-band signal. The pseudorange is this time interval multiplied by the speed of light in free space. [52] identified the following components in the pseudorange observation.
1. The geometric range, which is the distance between the phase centers of the transmitting antenna on the satellite and the receiving antenna employed by the user. This is the component of the pseudorange that is of primary interest to the navigation user.

2. The receiver clock time offset from GPS time.

3. The satellite clock time offset from GPS time.

4. Relativistic effects.

5. Propagation delay/advance caused by tropospheric refraction.

6. Propagation delay caused by ionospheric refraction.

7. Multipath errors introduced by signal reflections from structures in the vicinity of the antennas.

8. Receiver-dependent propagation delays such as the signal propagating through the preamplifier and antenna cable.

9. Receiver measurement biases.

10. Satellite transmission biases among frequencies.

11. Selective Availability (SA) effects, if present. Intentional SA errors on GPS satellite timing and ephemerides were turned off under a U.S. presidential directive on 1 May 2000.

12. Background wideband noise generated by the receiver components.

The phase observation can be considered to be a precise version of the pseudorange observation, with an additional unknown parameter attached: an integer wavelength bias. The receiver phase observation is a cycle count relative to an arbitrary receiver reference epoch. There is no information in the phase measurement about satellite transmission time except what is provided by the pseudorange. Ideally, the arbitrary integer phase offset could be deduced by comparing the phase count with the pseudorange. However, the inherent pseudorange noise is large enough to make this process difficult even under the best conditions. Also, the ionospheric refraction component must be considered, because ionospheric refraction delays the pseudorange, but advances the phase. A discussion of the possibility of using pseudorange to determine the phase integer bias is given by [53].

Except for the geometric range, all of the items listed above can be considered to be sources of error. Fortunately, most can be accounted for and reduced to an acceptable level. The goal for accurate absolute positioning is to faithfully separate the geometric range from the propagation errors. Besides accurate pseudorange observations, in order to perform the absolute position solution, the satellite position is required at the time of transmission. A geometric range with zero error will still provide erroneous user position solutions if the satellite position is not precisely known. Under most user conditions, in the ab- 
sence of SA, the satellite ephemerides errors and clock offset errors are the largest sources of absolute positioning error.

\section{GPS Absolute Positioning Algorithms}

In comparison to the number of GPS relative positioning algorithms in existence at this time, the number of absolute geodetic positioning algorithms is somewhat small. Prior to 1 May 2000, these algorithms could be categorized into two distinct categories: those developed by the $\mathrm{DoD}$, for which the effects of SA are removed before the process takes place, and those developed by research groups or universities or implemented by manufacturers, for which the effects of SA are handled in other ways. The distinction is no longer important now that SA has been set to zero.

The raw satellite observations generally consist of the pseudorange and phase measurements described previously. Several different combinations of these data types are used for absolute point positioning, however, and each point-positioning algorithm known to the authors' forms a different combination of the raw data types to use as an observable in the estimation process. While the scope of this paper will not allow a complete description of each of these combinations, a general outline of the observables and estimation algorithms will be provided.

The simplest way to perform absolute positioning is with the epoch-by-epoch navigation solution. Though unsophisticated mathematically, this approach has several advantages. It solves for only four parameters: the three components of position and the local clock offset. Since there are only four unknowns, four satellite pseudoranges are enough for a solution, though data from all satellites in view may be used in a least-squares algorithm. Since each epoch is treated independently, the navigation solutions can be found with uniform accuracy regardless of the user's motion. If the receiver is stationary, the individual position estimates can be averaged to reduce the impact of random errors. Propagation effectssuch as tropospheric and ionospheric refractionmust be modeled if single-frequency observations are used. When dual-frequency observations are available, the ionospheric refraction can be computed and essentially eliminated. The satellite positions and clock offsets are obtained either from the broadcast satellite ephemerides or from a set of precise ephemerides and clock states if timeliness is not a concern.

If the broadcast navigation messages are used and the tracking data are not retained, a user can still improve the accuracy of these navigation solutions by using precise ephemerides and clocks, if a record of the satellites tracked is kept. The Precise Absolute
Navigation technique [54], was developed specifically for this purpose.

Exclusive use of the pseudorange may lead to solutions being strongly influenced by multipath effects if a hostile antenna environment is present. Smoothing the pseudorange observations with phase measurements can reduce this effect and has been used successfully in many applications. In order to exploit the lower noise phase observation, range differencing can be used. Since the unknown integer phase bias is constant while the receiver tracks the satellite signal (ignoring cycle slips), time differences of the phase produce a range difference observation between adjacent epochs. The range difference over a time interval is akin to an average velocity measurement. At least two epochs are required to construct the range difference, though many observations at equal intervals are usually used.

Another technique used to construct an observable for point positioning uses the ionospheric-free range difference from phase, along with the ionospheric-free pseudorange, to transfer each pseudorange observation to a common epoch. At the common epoch, all of the transferred pseudoranges are averaged to minimize the uncorrelated pseudorange errors (measurement noise and some forms of multipath effects) that appear in each of the observations. This average pseudorange can then be transferred back to all observation epochs through the range difference observations. This technique is useful if the phase integrity is such that cycle slips, and integer phase ambiguity resets are few.

A type of double differencing of the phase observations has also been successful. For this double differencing, the first difference is the between-epoch range differences based on phase data, then the range differences are differenced between satellites. The differencing between satellites removes effects that are common to all satellites, such as the receiver time offset. Multipath effects are reduced because only phase observations are used. However, the doubly differenced observable requires very good geometrical strength over several hours in order to produce a satisfactory position accuracy.

In the early 1990 s, the routine absolute accuracy of geodetic point positioning was in the vicinity of $1 \mathrm{~m}(1 \sigma)$. Today (2002), with the precise ephemerides and corresponding satellite clock states, $12 \mathrm{hr}$ of observations, plus recent improvements in several algorithms known to the authors, absolute point position accuracies at the $5-\mathrm{cm}$ level have become routine. For further details on several of the point positioning algorithms discussed here, the reader can refer to: [55 - 64]. 
Navigation, Journ. of the Inst. of Navigation, Vol. 49(1), 7-34, Spring 2002

\section{DIFFERENTIAL POSITIONING}

Differential positioning is not new. Prior navigation systems - such as Omega, Loran C, and TRANSIT-were improved via differential implementations. In each case, just as with GPS, the accuracy is improved by using a monitor receiver to measure the errors at a reference site and to transmit corrections derived from those measurements to the differential user receiver. Because of the strong spatial correlation of the errors, the accuracy of the user receiver is substantially improved. The civil GPS user was further motivated to develop differential positioning techniques with the advent of anti-spoofing and, the now removed, selective availability, which intentionally degraded accuracy. This and later sections discuss some of these techniques.

It is stated in almost all differential GPS (DGPS) descriptions that the position of the monitor receivers must be determined by precise survey. However, this is not necessarily the case. DGPS is fundamentally a relative positioning system. The monitor receiver could be (and sometimes is) located on a moving vehicle such as a ship, airplane, or satellite. In this case, the measurement corrections supplied to the user, who is positioned relative to that vehicle, are the negative of the measurement residuals from the vehicle position computation. When multiple monitor receivers are used they, of course, must be located accurately relative to one another. The requirement for accurate surveying of the monitor receiver position arises only from the desire to transform the relative positioning accuracy into an absolute accuracy.

One can find in the literature descriptions of a GPS position differential technique often referred to as "Relative GPS," which makes use of corrections to the position rather than corrections to the measurements used in computing the position. This requires the user receiver to use measurements from exactly the same satellites (some of which may not be visible to the user). The alternate way to implement DGPS is to send corrections from the monitor receiver rather than the raw pseudorange measurements. This avoids sending the monitor receiver location (assuming the tropospheric refraction effects are removed at the monitor receiver before generating the corrections).

DGPS techniques can be used in both static and kinematic applications and may involve either pseudorange or carrier-phase measurements, or both. The static techniques are addressed first, then the kinematic techniques.

\section{Static Techniques}

Static DGPS positioning was probably the first commercial application of GPS. Because the application did not require continuous availability, it was economically attractive even while only a few GPS satellites were in orbit-long before the system was declared operational. The most common use for static DGPS was in surveying. A monitor receiver was placed at a known reference location, and a second receiver was placed at a site whose position was to be determined [65]. Measurement data were recorded at both sites and then brought back to an office for subsequent processing. The primary measurement data needed for survey quality results were the carrier-phase measurements. However, the pseudorange (or code) measurements were often used to aid the processing.

\section{Pseudorange Differences}

The pseudorange (or code) measurements were used in many different ways in the early survey applications. Quite often the purpose was to measure the vector difference between two surveyed points. In this relative positioning task, the location of the monitor receiver is not required to attain high accuracy. Thus, the position of the monitor site was often computed using the undifferenced pseudorange measurements. This was followed in many processing programs by a preliminary differential pseudorange solution. This first stage in computing the vector difference between the monitor site and the user site used the double difference of the pseudorange measurements or some nearly equivalent process.

Differencing the measurements allows the removal of satellite and receiver clock errors. By taking the difference across satellites of the measurements taken at each site, one eliminates the common effect of the receiver clock variation. By then differencing these differences (double differencing) across sites, the variation in the satellite clocks is eliminated. An essentially equivalent process is to use the undifferenced measurements and to select either a satellite clock (preferable) or one of the receiver clocks as the standard clock and then to solve for clock differences as part of the solution process [66].

\section{Carrier-Phase Differences}

The next stage in the process of computing the vector difference between a monitor site and a user site is to use the more precise carrier-phase measurements. The carrier-phase measurements are much more accurate than the pseudorange measurements because they are much less affected by multipath (reflection) effects [67]. However, they suffer a significant problem-specifically, they are ambiguous at the whole-cycle level (or half-cycle for early codeless receivers). One way of understanding this ambiguity is to recognize that the phase measurement is the integral of the difference in phase of the signal received 
and the phase of the local clock scaled to the transmitted frequency. The fractional phase relationship

of this integral is well defined. However, the wholecycle constant of integration is not.

The simplest way to overcome the whole-cycle ambiguity problem is to form "triple differences." The triple difference is obtained by differencing measurements: (1) across user and monitor receivers, (2) across satellites, and (3) across time. Note that the order of differencing (across receivers, across satellites, and across time) does not affect the final composite measurement. Because the whole-cycle ambiguity remains the same for all carrier-phase measurements to a given satellite, differencing sequential measurements (differencing across time) cancels the whole-cycle ambiguity bias. Unfortunately, this simple triple-difference solution is geometrically weaker than other alternatives. In fact, its geometrical strength is a function of the time interval used in the differencing process. In spite of this geometrical weakness, this triple-difference solution is generally significantly more accurate than the differential code solution described above. It is also possible to form the single time difference and, as described above, choose one of the clocks as the reference clock, and then solve for the clock differences as part of the solution process.

A solution stronger than the triple difference can be obtained for the vector difference between the two sites, still without resolving the whole-cycle ambiguities. There are many ways to obtain this equivalent solution. One of the simplest ways, although it causes the number of solution parameters to increase significantly, is to avoid the time differencing of the measurements and instead include in the solution parameters an ambiguity bias parameter for each set of sequential carrier-phase measurements to each satellite. In using this approach, a new bias parameter is required any time continuous phase lock is not maintained. There are several other alternative ways of obtaining a mathematically-equivalent solution. Perhaps the simplest of these alternatives is to form the sequential time difference of the carrier-phase measurements. However, during the processing of these measurements, the proper weight matrix is used to account for the sequential measurement cross correlation (of -0.5) induced by that differencing. In this approach, the specific ambiguity bias parameters need not be included in the solution, but they can be found by taking the resultant position and computing the range to the satellites in units of whole cycles.

Finally, the strongest solution arises when the carrier-phase measurement ambiguities are specifically determined to the correct whole-cycle value. A multitude of methods can be found in the literature for resolving the whole-cycle ambiguities. One of the simplest for the static user, although not the most robust, is simply to round the values of the biases computed in the prior solution (whether explicitly or implicitly determined) to obtain a whole-cycle integer value for each ambiguity. In some software, this is accomplished by fixing one whole-cycle ambiguity at a time and then recomputing the solution before fixing the next one.

It is not difficult, though the processing can become quite complex, to extend the single-monitor/ single-user scenario discussed above to the multiplemonitor and/or multiple-user environment.

\section{Kinematic Techniques}

Differential code or pseudorange measurements are often used when the user receiver is no longer static but moving (i.e., kinematic). As currently used in the literature, however, kinematic DGPS almost always refers to a moving user employing differential carrier-phase measurements. Differential code techniques for the moving user are usually referred to as either Local-Area Differential GPS or Wide-Area Differential GPS. The most common reference to kinematic carrier-phase techniques is real-time kinematic GPS processing. The differential aspect is simply implied by common usage.

\section{Local-Area Differential GPS (LADGPS)}

The U.S. Coast Guard has developed a number of LADGPS monitor sites that provide pseudorange corrections for GPS users in the area adjacent to the monitor sites [68]. Local, in this context, can apply to a radius of several hundred miles. These Coast Guard beacons provide code or pseudorange corrections in the standard RTCM format for each GPS satellite on at least the L1, or primary, frequency. Tropospheric refraction effects are generally computed by the user for both the monitor and his own receiver using a mathematical model. Ionospheric refraction effects are generally ignored because they are strongly correlated and, therefore, largely cancel over the local area distances involved. There are many similar networks of LADGPS monitors around the world. The primary users tend to be local marine traffic, but farmers and other commercial users are becoming significant beneficiaries.

\section{Wide-Area Differential GPS (WADGPS)}

The U.S. Federal Aviation Administration (FAA) is developing a WADGPS system that is referred to as the Wide-Area Augmentation System (WAAS). Japan is developing a similar system referred to as MSAS, and the European nations are developing a similar system referred to as EGNOS. A number of commercial WADGPS systems have also 
been developed by and for commercial applications.

Typically, a WADGPS implementation will have between 10 and 50 monitor stations across a continent-wide area. Generally, the monitor stations use dual-frequency, L1 and L2, GPS receivers, even though the corrections they provide are usually for L1-only user receivers. In the WAAS, the dualfrequency monitor receivers are used to provide measurements of ionospheric refraction effects, which are then used to provide parameters to drive a model of the effects in the user receiver. In addition, the monitor station measurements are used to compute orbital corrections, which are provided to the user at a slow rate. Thus, the WAAS user is provided with three types of corrections: (1) a fast-rate clock correction, which removes the rapid (SA) distortions in the users' L1 pseudorange measurements; (2) parameters used to compute an ionospheric refraction correction; and (3) slowly varying parameters to compute corrections to the GPS broadcast ephemerides. The WAAS users are responsible for computing their own tropospheric refraction effects with a specified algorithm. The accuracy available from a well-designed WADGPS typically has a standard deviation of about $1 \mathrm{~m}$ in each horizontal axis and about 2 or $3 \mathrm{~m}$ in the vertical axis.

In both the LADGPS and WADGPS implementations, the GPS carrier-phase measurements play a subsidiary role. Specifically, they are used to smooth, and thereby remove, some of the multipath effects normally present in the code measurements [69].

\section{Real-Time Kinematic (RTK) Differential GPS}

Navigation at the centimeter level is possible using differential carrier-phase techniques [70 - 76]. As indicated above, this requires the resolution of the whole-cycle ambiguities. There are two primary methods to resolve the whole-cycle ambiguities [77]. Both are generally practical over distances of only 10 to $20 \mathrm{~km}$. The first method is to use a search procedure in the position-solution domain. Generally, the code measurements are used to aid this process by determining the limits of the search. A wide variety of variations of this technique can be found in the literature.

A second method is to use the code measurements on a satellite-by-satellite basis to resolve the carrier-phase, whole-cycle ambiguity directly. This technique becomes the preferred method if the user has a dual-frequency receiver. The use of two frequencies allows the formation of a beat (difference) frequency carrier-phase measurement with a substantially longer wavelength, which is often referred to as the wide lane. Over distances of less than 10 to $20 \mathrm{~km}$, the ionospheric refraction effects are largely removed, and one can determine from the wide-lane, whole-cycle solution the value of the narrow-lane (L1

or L2 or the average of L1 and L2), whole-cycle ambiguity.

The second method is aided by the fact that the code measurements can be smoothed via the carrierphase measurements. For single-frequency receivers, this smoothing is limited by the ionospheric divergence of the code and carrier-phase measurementsi.e., the ionosphere affects the code pseudorange measurements opposite to the way it affects the carrier-phase measurements. However, a linear combination of the L1 and L2 carrier-phase measurements can always be found that exactly matches the ionospheric refraction effects present in any specific linear combination of the L1 and L2 code measurements (and vice versa). This means that the pseudorange (code) measurements can be smoothed indefinitely to remove the multipath effects by using the matching linear combination of the carrier-phase measurements. With this smoothing process, it does not take long with a high-quality GPS receiver to obtain a smoothed-code measurement (with ionospheric refraction matched to the wide-lane carrier-phase measurement) capable of resolving the proper whole cycle of the wide-lane carrier-phase measurement. Additionally, over short distances, as described above, this resolved wide-lane measurement can be used to determine the whole-cycle ambiguity of the narrow-lane measurements.

For this second method, the whole-cycle ambiguities can be verified when measurements to five or more satellites have been obtained. If the whole cycles are correct, then the measurement residuals will be small. If one or more have been resolved incorrectly, the measurement residuals will be much larger. In fact, one of the most significant benefits of the dual-frequency, code-assisted, whole-cycle ambiguity resolution is this simple residual verification process. By contrast, since the search method uses the measurement residuals directly to find the best solution, it becomes more complicated to verify that it is the correct solution. Most implementations of the ambiguity search process use the ratio between the residuals of the best solution to the residuals of the second-best solution as a measure of the confidence in the choice of the best solution.

In any case, once the whole-cycle ambiguities have been determined, the carrier-phase measurements provide a navigation solution of about $1 \mathrm{~cm}$ in each axis of the horizontal position and about $2.5 \mathrm{~cm}$ in the vertical position. This accuracy decreases slowly as the baseline separation distance increases beyond about $10 \mathrm{~km}$. But it is not the position accuracy that limits the technique. The limiting factor is 
the ability to resolve the whole-cycle ambiguities as the ionospheric refraction begins to affect the widelane, whole-cycle resolved measurements differently than it affects the narrow-lane, carrier-phase measurements.

From the discussion above, it becomes clear that RTK carrier-phase DGPS, using integer cycle resolution, can provide a solution that is more accurate than any other GPS navigation technique. However, the baseline separation distance over which the technique can be applied is generally limited to about $10 \mathrm{~km}$ [78]. Methods that incorporate a reference receiver network have been used to extend the distances to the roving user. Some approaches use the additional reference station measurements to improve the tropospheric and ionospheric corrections and model the satellite ephemeris errors [79. Other approaches incorporate the measurements into a single site [80] or a virtual reference site that is generally placed near the roving user $[81,82]$. These techniques extend by a factor of 3 to 5 the baseline distance for reliable integer cycle resolution.

\section{Long Baseline, Multireference Kinematic DGPS}

There are a number of remote-sensing applications that require both precise positioning and long baselines. These applications include large area surveys in polar areas, oceans, or other areas where short-baselines are either difficult or costly to deploy. Pseudorange-based WADGPS techniques are not sufficiently accurate. Decimeter-level accuracy has been demonstrated for long baselines (greater than $1000 \mathrm{~km}$ ) using a dual-frequency, carrier-phase measurement approach [83]. Here, pseudorange measurements are used only to provide initial estimates and assist with cycle slip detection and correction.

The approach uses an estimation procedure known as floating and positions the dynamic user with respect to multiple accurately positioned reference sites. The reference site absolute positions are obtained to an accuracy of a few centimeters. This allows the multiple sites to be used interchangeably in the dynamic user solution and mitigates, to a degree, the problem discussed earlier of the number of satellites in common view. With multiple reference sites, especially if they are in various directions with respect to the dynamic user, the satellites in common view become more numerous at long baselines.

Real-valued biases for the ionosphere-free combination of L1 and L2 (or "L3") double-differenced phase measurements are estimated in a joint solution with the dynamic trajectory. Other biases due to the effects of reference station position errors, satellite orbit errors, and tropospheric refraction errors are also estimated simultaneously. The differential effect of the solid earth tide is also included.

For long baselines, the accuracy of the solution is dependent on the number of satellites in common view and the corresponding differential satellite geometries between the dynamic user and reference sites or the differential position dilution of precision (PDOP). Since in long-range navigation it is necessary to solve for more parameters than just the coordinates of the moving antenna and receiver clock error, at least five satellites in common view are needed. If the distribution of satellites allows, the elevation cutoff of 17 degrees may be preferred to the usual 15 degrees to reduce the presence of multipath effects and cycle slips to which the long-range solutions can be particularly sensitive. Further, a significant amount of processing time-over $20 \mathrm{~min}$ of data collection-is required to accurately estimate the measurement and error biases, while simultaneously determining the dynamic user trajectory.

Test results using precise postfit satellite ephemerides suggest that most of the time the kinematic positions calculated with the long-range techniques were within $10 \mathrm{~cm}$ of the true positions, and that the RMS accuracy for baselines over $500 \mathrm{~km}$ was better than one part in 10 million of the baseline length [84]. These results depend on having more than four satellites in view and on favorable geometry (e.g., differential PDOP<8). Good results of decimeter-level accuracy can be obtained with the broadcast ephemeris if readjusted as part of the kinematic solution. Applications in real time and on a global scale are discussed in a later section.

\section{STATUS OF MAPPING AND SURVEYING AP- PLICATIONS}

Currently, the fields of surveying and mapping are being transformed by a number of new and innovative technologies, including Geographic Information Systems (GIS), high-resolution remote sensing, and GPS. Of these, GPS has had the most important and immediate impact because of both cost savings and accuracy improvements over previous positioning technologies and techniques. The single most powerful feature related to GPS, which is not true of traditional surveying techniques, is that its use does not require a line of sight between adjacent surveyed points. This factor is very important in understanding the impact that GPS has had on the surveying, mapping, and GIS communities.

As previously stated, GPS has been used by the surveying and mapping community since the late 1970 s when only a few hours of satellite coverage were available. It was clear even then that centimeter-level accuracy was obtainable over very long baselines (hundreds of kilometers). In the early 
1980s, users of GPS faced several problems: the cost of GPS receivers; poor satellite coverage, which resulted in long lengths of time at each survey location; and poor user-equipment interfaces. Today, instantaneous measurements with centimeter accuracy over tens of kilometers and with one part in $10^{8}$ accuracy over nearly any distance greater than $10 \mathrm{~km}$ can be made. The cost of "surveying and mapping-level" receivers in 1999 ranged from $\$ 10,000$ to $\$ 25,000$, and these costs are falling. Practitioners are developing numerous new applications in surveying, such as the use of GPS in a kinematic (real-time) mode to determine the elevation of terrain prior to grading [85]. (See THE FUTURE section )

Traditional land surveying is increasingly being accomplished using GPS because of the continuous reduction in receiver costs, combined with an increase in user friendliness. This trend towards the use of GPS for surveying and mapping has enhanced the volume of survey receiver sales. (Land surveyors outnumber control surveyors by at least one order of magnitude.) This usage has also increased the accuracy and accuracy requirements of surveying in general. The fact that accuracy requirements have increased comes from the phenomenon that accuracy requirements tend to increase as the availability of better accuracy increases.

The standard surveying and mapping activities that are enhanced by GPS include surveying for subdivisions, highways, planned communities, etc. To date, GPS has not been used widely for single-lot or mortgage surveys. This is because the accuracy improvement is marginal for distances of $30 \mathrm{~m}$ or fewer, there may be problems with foliage attenuation, and the cost of close-range GPS operations is still slightly higher than traditional techniques. However, it is likely that in the future GPS will be used for such activities.

In general, the availability of higher GPS accuracy has influenced various mapping and surveying requirements for three reasons: (1) people want the state of the art; (2) past requirements were in some cases dictated by the cost of acquisition; and (3) if higher accuracy can be obtained, multiple purposes can be satisfied. As an example of requirements changing as a function of new capability, consider a problem [85] of facilities management, which deals with the inventory of transportation features such as the location and attributes (type, condition, and so forth) of a guardrail along a highway. Previously, the location was "required" by transportation departments to be accurate to $\pm 6 \mathrm{~m}(20 \mathrm{ft})$, which is generally the best that is possible from scaling or plotting on a 1/24,000 United States Geological Survey quadrangle. Using differential techniques, a GPS position can easily be obtained in a real-time, dynamic envi- ronment to within $\pm 1.5 \mathrm{~m}(5 \mathrm{ft})$. Users now realize that if accuracies of $\pm 0.3 \mathrm{~m}(1 \mathrm{ft})$ can be obtained (and they can), the length of the guardrail, in addition to its location, can be obtained so that if the guardrail needs to be upgraded or replaced, an accurate estimate of the cost is available. This kind of application is growing rapidly because GPS's accuracy and capability is becoming understood, and the technology is being applied to various problems. Applications of this kind are widespread and growing in the GIS community.

\section{Geographical Information System (GIS) Applica- tions}

Today, in most developed countries, there exists a concept generally known as a National Spatial Data Infrastructure (NSDI) or simply a Spatial Data Infrastructure (SDI). As defined by the [86], the NSDI is a process that includes spatial data collection, management, and distribution. Obviously, the location of points of interest is central to this process. GPS, in many of its modes of operation satisfies nearly all the positional requirements of an SDI. In this context, the classical definitions of mapping should probably be expanded because of the many applications that do not require high or even moderate accuracy. These applications are sometimes known as "GIS projects" and are usually focused on environmental, taxation, natural resource planning, and civil infrastructure (facilities management) issues. Many demographic studies that require approximate positioning are easily satisfied by GPS.

Accuracy requirements for surveying, mapping, and GIS applications are generally satisfied at this time. The quest for better and better accuracy will continue, but any reasonable distance can currently be measured, with significant care, to one part in $10^{8}$. As noted above, GIS applications are fully satisfied.

\section{GEODYNAMICS}

Everyone knows that the earth is rotating, but how many are aware that the earth's pole moves a few centimeters per day, or that the state of Nevada is stretching by several millimeters per year? Far from being trivial, this type of information has practical and societal use, whether it is navigating interplanetary spacecraft using NASA's Deep Space Network, or identifying areas at risk of having large earthquakes. Geodynamics is the study of processes involved in the rotation and deformation of the earth. Geodesy has, in a real way, been reinvented to meet the extraordinary accuracy requirements of geodynamics. This has not only benefited geodesy, but the 
technology has spun off into various aspects of positioning and navigation.

This section does not focus on specific geodynamics investigations using GPS. Rather, it emphasizes (1) the principles of geodynamics and global geodesy and their close relationship as scientific disciplines, and (2) some of the historical and technical developments that have allowed GPS to become a valuable tool for geodynamics. For examples of geodynamics applications of GPS and recent results, the reader is referred to the University NAVSTAR Consortium's (UNAVCO's) online brochure:

http://www.unavco.ucar.edu/community/brochure and the review paper by Segall and Davis [87]. Geodynamics is literally the study of forces that govern the motion of the earth's components. Although the emphasis is on the solid earth, interactions with all the earth's "spheres" must be taken into account. It is the goal of geodynamics to understand the earth's rheology, structure, driving forces, and resistive forces; as well as the interaction among the solid earth atmosphere, oceans, and ice sheets.

Geodesy is commonly defined as the study of the shape of the earth and its gravity field, and is therefore intrinsically connected to geodynamics. This is even more so for space geodetic techniques, such as GPS, which can be used to observe the earth on a global scale.

GPS contributes to geodynamics through comparing the observed and modeled motion of the earth's surface. Since the observed motion of the earth's surface will represent the sum of the various effects, it is clear that geodynamics must be modeled as a whole, even when investigating a specific problem. This creates a rich area of interdisciplinary research.

As the precision and coverage of GPS stations has improved over the last two decades, the depth and breadth of GPS geodesy's application to geodynamics has increased correspondingly. It has now matured to the point that it is viewed as an important and often primary tool for understanding the mechanics of earth processes.

Conversely, geodynamics models are essential to GPS geodesy; as such, models are embedded in the reference systems we use to define high-accuracy positions. For example, if the reference system did not account for the tidal deformation of the solid earth, the coordinates of some stations could vary as much as $\sim 10 \mathrm{~cm}$ in the time frame of several hours. Therefore, reference systems to enable high accuracy geodetic positioning have developed in parallel with progress in geodynamics, which in turn depends on geodetic positioning. This relationship is inextricable. Global geodesy is just as essential for geodynamics as the converse.

\section{GPS GEODESY'S GEODYNAMICS HERITAGE}

From a historical perspective, GPS geodesy is very different than, say, GPS navigation, or other branches of GPS positioning. GPS geodesy development drew greatly from the fields of physics, astronomy, and spacecraft navigation. GPS geodesy can be considered a blend of two earlier space geodetic techniques: Very Long Baseline Interferometry (VLBI) and Satellite Laser Ranging (SLR). Early developers of geodetic VLBI demonstrated centimeter-level precision in the late 1970s [88]. Geodetic VLBI and SLR were developed through the 1980s as part of the NASA Crustal Dynamics Project, specifically for geodynamics investigations. GPS was viewed by NASA and other federal agencies as an economical alternative to VLBI and SLR, and thus provided funds to develop geodetic receivers and software.

The VLBI technique, similar to GPS geodesy, measures the relative time of arrival of radio waves propagating from a source in space to at least two instruments on the ground. Models for signal propagation, including geometry, relativistic effects, and tropospheric refraction of the VLBI signal, were initially implemented by GPS geodetic software. Developments in tropospheric propagation for either technique have generally benefited the other (see POSITIONING section).

However, the VLBI sources are not satellites, but quasars, effectively at infinite distance. Thus the directions to them can, in principle, be determined with far greater precision than to the GPS satellites, with their more complicated dynamics. On the other hand, orbit models are a function of the earth's gravity field; hence GPS stations, unlike VLBI stations, can be positioned relative to the center of mass of the earth (see ORBIT DETERMINATION section).

As VLBI is a radio technique, VLBI technology was adopted in NASA's earliest GPS geodetic receivers. The SERIES receiver, developed by MacDoran at the JPL in 1979, pointed at one source at a time using a directional antenna [89]. Many key principles of the modern GPS geodesy were based on the omnidirectional instrument, MITES, proposed by Counselman and Shapiro in 1979 [90]. This was developed by the Massachusetts Institute of Technology (MIT) group into the Macrometer, which proved centimeter-level accuracy using the innovative doubledifference method (see POSITIONING section) for eliminating clock bias [91]. An interesting historical point is that the double-difference method has its origins in a method also proposed by Counselman for radio navigation of the Apollo mission [92].

In parallel, JPL developed an equivalent approach, known as white-noise clock elimina- 
tion/estimation, based on the Householder transformation [93]. This also has its pre-GPS origins as a method of bias elimination for NASA's spacecraft navigation. GPS textbooks typically ignore white-

noise clock estimation, yet it has increasing relevance to the timing community.

Contrary to initial skepticism, the GPS orbits eventually proved to be no more problematic than SLR, despite additional modeling problems. This is because GPS geodesy uses far more stations and satellites than SLR, and can derive geodetic quality positions using orbit arcs, which are much shorter (24 hr) than for SLR (several days or weeks).

GPS geodesy also benefited from earlier work on reference system conventions already established through a combination of astronomical observation, VLBI and SLR observation, and geodynamics modeling. In general, earth models such as tidal deformation are required by all global geodetic techniques, so GPS geodesy was in a position to exploit what had already been learned.

The space geodetic pioneers of VLBI and SLR deserve credit from the developers of GPS geodesy for much of the initial technology [94]. Even so, some of the inherited ideas from VLBI and SLR required some rethinking if GPS were to achieve its full potential.

\section{HIGH PRECISION FOR GEODYNAMICS}

GPS geodesy as a tool for geodynamics requires (1) subcentimeter positioning precision to detect geophysical motion which, in turn, requires (2) a global network of stations to enable POD. Broadly speaking, the 1980s developed the technology required for (1), and the 1990s developed the infrastructure and global cooperation required for (2).

The development of geodetic GPS during the 1980s was characterized by intensive hardware and software development with the goal of subcentimeter positioning accuracy, over increasingly long distances. Several high-precision geodetic software packages that were developed around this time are still in use and far exceed the capabilities of commercial packages. These include the BERNESE developed at the University of Berne [95], GAMIT developed at MIT [96], and GIPSY/OASIS developed at JPL [97].

The first geodynamics experiments using GPS were carried out during the second half of the 1980s using survey campaigns in areas of tectonic interest [99-101]. These campaigns were to be repeated in later years, during which time the effects of geodynamics would be revealed. Such experiments spurred the development of analysis techniques to improve precision at the level required by geodynamics. Im- portant developments during these years include ambiguity resolution over long distances [102 - 104], POD (see ORBIT DETERMINATION section), and troposphere modeling (see POSITIONING section).

Developments towards high precision in the 1990s include (1) truly global GPS solutions (discussed below) made possible by the completion of the Block II GPS constellation and, simultaneously, installation of the International GPS Service (IGS) for Geodynamics global network in 1994; (2) globalscale ambiguity resolution [105]; (3) further refinement to tropospheric modeling [106] and the inclusion of tropospheric gradient parameters [107, 108]; (4) adoption of dual-frequency code receivers, as opposed to the squaring receivers of the 1980s [109];

(5) adoption of the low-multipath choke-ring antenna developed at JPL as the standard [109]; (6) improved orbit models, particularly with regard to GPS satellite attitude, and the tuning of stochastic models for solar radiation pressure (see ORBIT DETERMINATION section); (7) improved reference system conventions [110]; and (8) solution combination analysis for orbits [111] and station positions [112].

\section{GPS INFRASTRUCTURE AND COOPERA- TION}

Infrastructure development and tremendous international cooperation characterized the 1990s. GPS operations moved away from the campaigns, back to the model of permanent stations, familiar to VLBI and SLR. As the prototype receivers developed by research groups in the 1980s had become commercialized, the cost of installing a GPS station in the 1990 s had fallen to $\sim 25 \mathrm{~K}$, in contrast to the millions of dollars required for VLBI/SLR. Thus the longrange goal of the federal funding agencies was realized: dozens of GPS stations could be installed for the price of one VLBI station.

With the cooperation of $\sim 100$ research institutions around the world under the umbrella of the IGS, a global GPS network (GGN) (now at 200 stations) with a full geodetic analysis system came into full operation in 1994 [113]. This backbone, together with the regional stations located in areas of tectonic activity, such as Japan and California, form a globalscale instrument capable of resolving global plate tectonic motions $[114,115]$ and regional phenomena such as earthquake displacement $[116,117]$. As a result of this international cooperation, a culture of data sharing has developed, with data freely available for research purposes via the Internet from IGS Global Data Centers. Establishment of the Receiver Independent Exchange (RINEX) GPS standard measurement format [118] initiated this extensive international data sharing in 1989 [119]. 
Navigation, Journ. of the Inst. of Navigation, Vol. 49(1), 7-34, Spring 2002

While the IGS does not specifically carry out geodynamics investigations, it does provide an essential service without which geodynamics investigations would be very costly and difficult to carry out. The 1990s has seen the development of collaborations with specific geodynamics goals. Groups such as WEGENER [120, 121], UNAVCO, and the Southern California Integrated GPS Network (SCIGN) provide an umbrella for geoscientists using GPS geodesy as a tool. Such groups depend on IGS for their success; conversely, IGS depends on such users to justify its existence.

The infrastructure has indeed become quite complex, yet cooperative, and often with an efficient division between geodetic operations and geodynamics investigations. As a more recent example of how infrastructure is developing, solutions are being exchanged in a standard Software Independent Exchange (SINEX) format to enable the construction of combined network solutions [122] and, therefore, combined global solutions for earth surface kinematics [112]. Combination solutions have the advantage that (1) the processing burden is distributed among many groups who can check each other's solutions; (2) noise and errors are reduced through increased redundancy and quality control procedures; (3) coverage and density are increased; and (4) regional geodynamics can be interpreted in a self-consistent global context. It appears that this decade (2000s) will be focused on developing such combination solutions, and on the inversion of these solutions to infer geophysical parameters [123].

\section{GPS GLOBAL GEODESY-A MODERN PARADIGM}

During the 1990s, a modern way of thinking about GPS global geodesy [124, 125] has emerged out of necessity, to assist a more confident interpretation of geophysical signals [126]. From this viewpoint, we consider the GPS geodetic measurement in terms of the fundamental information content it can provide on global geodynamics, such as earth rotation, earth center of mass, and deformation of the earth's crust.

Consider a network of GPS stations, tracking all the GPS satellites. Using the GPS data, we can estimate the geometrical figure defined by the stations and the satellite orbits. That is, GPS provides information on internal geometry-including the distances between stations and the angles between baselinesand how these parameters vary in time. The elegant aspect of this geometrical picture is that it more closely relates to quantities that can actually be measured in principle, such as the time it takes for light to travel from one station to another. This con- trasts with coordinates, which are frame dependent, and therefore have secondary status.

Since GPS orbits (see ORBIT DETERMINATION section) can be well modeled over an arc length of a day (two complete orbits), we have access to an instantaneous inertial frame (called an inertial frame of date), which by definition, is the frame in which Newton's laws appear to be obeyed. Using such an inertial frame, the system can therefore determine the direction of the instantaneous spin axis of the earth (called the Celestial Ephemeris Pole (CEP)) with respect to the polyhedron. The direction of the CEP, relative to the global station network, wanders from one day to the next - a phenomenon known as polar motion. Moreover, the rate of spin of the earth about its CEP can also be estimated.

Finally, as discussed earlier, GPS is sensitive to the location of the earth's center of mass within the geometrical figure of the polyhedron [127]. The earth's center of mass is the dynamical origin of the force models used to compute the GPS satellite orbits (see ORBIT DETERMINATION section). GPS geocentric positioning is currently being used to correct tide gauge records for land movement, so that longterm sea-level change can be referenced to the earth's center of mass [128].

In practice, residual station motions are estimated in a "free network" adjustment [124, 125], and are then Helmert-transformed to a conventional frame [129]. For example, it is quite typical for global GPS results to be quoted with respect to the ITRF [130]. In turn, ITRF depends on SLR to align its coordinate origin with the earth's center of mass. Note that WGS 84 , and hence the coordinate origin, has in recent years become aligned to ITRF (see ORBIT DETERMINATION section). In summary, GPS global geodesy can well determine the shape and change in shape of the earth, as represented by a global network of stations. It can also resolve polar motion, rate of rotation, and to a lesser extent, the center of mass of the earth. These sensitivities provide the basis for GPS geodesy as a tool for various geodynamics investigations. The more predictable aspects of earth motion - such as precession, nutation, solid-earth tides, and the rigid-plate component of plate tectonic movement-are often specified by a conventional reference system, which can be further refined through observations using GPS and other space geodetic techniques.

\section{SPACEBORNE GPS GEODESY}

The first spaceborne GPS receiver system, called the GPS Package [131], GPSPAC, was launched in July 1982 on the LANDSAT 4 satellite. Three more 
GPSPAC units were successfully launched: one on LANDSAT 5 in March 1984 and two on DoD host vehicle satellites in 1983 and 1984. While these units performed exceptionally well, geodetic applications were limited due to the small number of GPS satellites in orbit at the time [132]. Spaceborne GPS geodesy started in earnest later in the 1980s. During this period, the GPS techniques being devised for centimeter-level geodesy were adapted to provide subdecimeter orbit accuracy for virtually any low satellite $[133,134]$. Spaceborne geodesy is now growing rapidly as more geodetic GPS receivers reach orbit. Here, we describe developments in four subcategories, including POD, measurement of the earth's gravity field, ionospheric imaging, and indirect enhancements to global geodesy and remote sensing.

\section{PRECISE ORBIT DETERMINATION (POD) AND SPACE ALTIMETRY}

Since the 1960s, the needs of earth remote sensing, and in particular of space-based altimetry to study ocean circulation, have stimulated advances in POD. Examples of ocean altimetric satellites over the years include the U.S. Seasat (1978) and Geosat (1985-1990); the European Remote Sensing satellites (1991-); the U.S.-French TOPEX/Poseidon (1992-); and the French-U.S. Jason-1 mission, launched in December 2001.

The essential observable of space-based altimetry is the height of the ocean surface, averaged over the radar footprint, relative to the reference ellipsoid. Of principal interest are the systematic departures of the ocean surface from the geoid-the surface of constant gravitational potential at sea level—caused by the forces that drive ocean circulation. This seasurface topography, which consists of a quasipermanent component reflecting the steady-state circulation and a variable component reflecting the time-varying circulation, is exquisitely subtle, with typical amplitudes of less than a meter stretched over wavelengths of hundreds of kilometers. Modern satellite radar altimeters can measure the instantaneous height of the sea surface with respect to the altimeter with a precision of better than $2 \mathrm{~cm}$, averaged over a footprint of several kilometers. But the height of the altimeter itself can vary by hundreds of meters around its orbit, confounding the translation of the altimeter range measurement to absolute sea surface height. To extract the most from the altimetric data, we must therefore track the satellite's absolute geocentric altitude continuously to a few centimeters as well. Since orbit error is a limiting factor in ocean altimetry, and altimeter precision will continue to im- prove, in 1991 an international science panel recommended the pursuit of "technology developments that lead to orbits of altimetric satellites with no more than 1-cm RMS error" [135].

The first descriptions of POD at a level of decimeters or better by GPS were [136, 137], who examined several DGPS tracking techniques. Since then, refinements have been introduced that better exploit the unique signals and observing strength of GPS, pushing POD performance close to $1 \mathrm{~cm}$. The basic techniques are summarized briefly below.

\section{Classical Dynamic Orbit Determination}

Conventional ground-based tracking systems seldom provide coverage from more than one direction at a time, and often provide no coverage. To supply the missing information for orbit determination, an orbit model must be fit to the tracking data. The most precise orbit estimation strategies employ orbit models derived from detailed models of the forces acting on the satellite, a technique known as dynamic orbit determination.

The technique begins with a set of tracking measurements along with models of the forces and satellite mass. Those models yield a model of satellite acceleration over time, from which, by double integration, a nominal or a priori trajectory is formed. To produce the orbit solution, the two constants of integration - the initial position and velocity-also known as the epoch state, are estimated.

\section{Kinematic Orbit Estimation With GPS}

Continuous three-dimensional coverage from GPS allows us to discard detailed force models in a kinematic orbit solution. Force model errors yield distinct postfit residuals - that is, discrepancies between the actual measurements and theoretical measurements based on the dynamic solution. Continuous data from multiple GPS satellites permit us to construct at every time point a full three-dimensional residual vector between the dynamic solution and a position estimate based only on the measurements. We can thus assemble a complete observed trajectory, geometrically, from a dynamic solution and its postfit residuals [138].

\section{Reduced Dynamic Orbit Estimation}

In general, the kinematic solution is suboptimal. We can often benefit by placing constraints on the estimated corrections, consistent with the force model errors. And if the model errors are correlated between time points, we can benefit further by representing that correlation in the stochastic adjustment. 
More generally, we can model the force corrections as colored (correlated) noise with a variance that reflects the expected force model errors. If the variance and correlation model are chosen carefully, we can fully exploit the dynamic information, while minimizing the consequences of dynamic model error. This reduced dynamic solution will, in general, yield the lowest overall error. Both versions effectively remove another altimetric bugaboo: geographically correlated orbit error, or error that is consistently greater over regions (often the oceans) where the dynamic models are biased [139].

\section{GPS Orbit Improvement and TOPEX/Poseidon}

When users determine their positions from GPS data collected by their own receivers, GPS ephemeris and clock errors can enter at a level of several meters. In the early days of GPS POD by the scientific community (c. 1992-1996), this was dealt with by adopting a global differential technique. A small global network of ground receivers, some at well-known locations, continuously tracks the GPS satellites. Data from the orbiter and ground are then combined in a grand solution for GPS and user orbits, some or all ground positions, phase biases, receiver and satellite clocks, and atmospheric delays. All positions are recovered in a consistent frame, and GPS orbits and clocks are removed as a direct source of error. As we shall see later, the flight GPS data, in addition to providing the host satellite orbit solution, can considerably improve the solutions for the GPS orbits as well.

This grand solution technique was first demonstrated in the early 1990s on TOPEX/Poseidon, which carried a six-channel dual-frequency receiver. Because the kinematic solution eliminates dynamic error, it is independent of gravity model error. The dynamic solution depends strongly on the gravity model and becomes limited by data noise and other errors only when gravity and other dynamic errors are small. The reduced dynamic strategy offers optimum performance. The estimated actual RMS altitude error achieved with GPS over the first year of the mission fell to about $2.5 \mathrm{~cm}$ when the gravity model was tuned with GPS flight data at the University of Texas [140]. The error from gravity modeling on TOPEX/Poseidon is now believed to be well under $2 \mathrm{~cm}$.

Today, with the astonishing accuracy of the GPS orbit and clock solutions distributed by the IGS, this grand solution strategy is no longer needed. IGS solutions can be adopted without adjustment and precise low-earth orbit (LEO) satellite orbits can be computed directly from the flight data alone, with little or no performance penalty, vastly speeding POD solutions. Rapid-service IGS orbits are now available within hours of real time, permitting comparably fast, precise LEO solutions. JPL now distributes precise GPS orbits and clocks on an experimental basis over the Internet in real time. These are also available worldwide through Inmarsat. While these are at present several times less accurate than IGS final orbits (1- to 2-week delay), they are adequate for decimeter-level real-time POD [141]. As more real-time ground sites are added, this will improve further. Within years, a LEO satellite will be able to compute onboard a true real-time orbit with subdecimeter accuracy.

\section{Bistatic GPS Altimetry}

Spaceborne GPS receivers may one day perform altimetry directly by sensing GPS signals reflected off the oceans and ice sheets, a technique known as bistatic altimetry. Reflections received from low orbit are weaker than direct signals by typically 40-50 dB. A spaceborne receiver with a high-gain antenna can acquire reflected pseudorange data with a precision of several decimeters after a few seconds of averaging. (Ocean surface roughness generally prevents the use of phase data.) While this is far worse than the $2 \mathrm{~cm}$ of conventional altimeters, a single orbiter can observe up to a dozen reflections at once. A small constellation can cover the globe in a few hours, and in a few days can collect enough data to average the height error to a few centimeters, with a resolution of a few hundred kilometers, or several times better than TOPEX/Poseidon over ten days at the equator. This would make possible, for the first time, the detection and continuous observation of eddy-scale circulation.

Analysis has been performed recently at JPL of GPS reflections observed fortuitously by the Shuttle Radar Lab-2 in 1995. This may be the founding event of space-based bistatic GPS altimetry: the first carefully observed ocean reflection received from space $[142,143]$. The reflected signal provides a measure of the range and of the scattering about the specular point, which provides information on surface roughness and other quantities. To obtain ocean height from reflected pseudorange, we must accurately model the positions of the transmitter and receiver, and the effective reflection point [144].

\section{THE GEOID AND GRAVITY ESTIMATION}

There is a second element to confound ocean altimetry: the geoid. Undulations of the geoid with respect to an ideal ellipsoid are on the order of $100 \mathrm{~m}$, or 100 times those of the dynamic topography. Accurate knowledge of the geoid is therefore essential 
to expose the permanent component of ocean circulation. Since the time of the first earth satellites, observations of deviations in a satellite orbit from an ideal ellipse have been used to elaborate our models of the gravity field [145 - 147]. The more precisely we can observe those variations, the more precisely we can reconstruct the field. It is the nature of the gravitational potential that precise knowledge of the gravitational signal for one orbit geometry does not imply comparable knowledge for other geometries. We therefore require tracking data from a variety of orbits to recover a general model of the global field. New satellites, including the U.S.-German Gravity Recovery and Climate Experiment (GRACE) twin spacecraft mission, carrying advanced GPS receivers will permit useful improvement of current gravity models.

\section{IONOSPHERIC IMAGING}

Among the most anticipated ancillary benefits of spaceborne GPS is comprehensive three-dimensional imaging of the earth's ionosphere. Apart from its inherent scientific interest, the ionosphere is of concern as an error source for single-frequency altimeters and GPS users, and as a potentially disruptive influence on radio communications. Today's two-dimensional global ionospheric maps derived from upwardlooking, dual-frequency GPS ground data [148], while they have revolutionized ionospheric imaging, provide little useful information on the vertical structure. In contrast, spaceborne receivers directed towards the earth's limb will provide copious horizontal cuts, tracing out the vertical electron density in surpassing detail. The combined space and ground GPS observations will provide enveloping coverage [149, 150].

\section{ANCILLARY BENEFITS FOR GPS GEODESY}

Spaceborne data can provide other enhancements for GPS geodesy. Studies in the 1980s revealed that data from a low orbiter could improve solutions for GPS orbits, ground positions (particularly the vertical component), and the geocenter [151, 152]. Since ground receivers move at a rather stately pace with respect to the GPS satellites, many hours (typically 24) of data are needed to compute GPS orbits of the first quality. A low orbiter, by contrast, moves swiftly, with revealing dynamics, often seeing all GPS satellites in less than $2 \mathrm{hr}$. These dynamically and geometrically powerful data can sharply reduce the time needed to obtain quality GPS orbits and improve their accuracy, with consequent benefits to derived geodetic products. While this was of much interest at a time when grand, full-orbit solution strategies were the rule in GPS geodesy, it is less so today when high-quality IGS orbits are continuously available, and fewer users compute their own. It is likely, however, that the IGS orbits, particularly the rapid and real-time products, will improve further when high-quality GPS data from multiple low orbiters are routinely included in the solutions.

Apart from the indirect benefit of improved GPS orbits, spaceborne GPS provides unique value in determining the geocenter. Note that any earth satellite follows a nominally-elliptical orbit with one focus at the geocenter. At present, the $\mathrm{z}$ component of the geocenter (the component along the spin axis) is less well determined by ground-based GPS than the $\mathrm{x}$ and $\mathrm{y}$ components because the $\mathrm{x}-\mathrm{y}$ solution is strongly aided by the earth's rotation, while $\mathrm{z}$ must be inferred only from the distant, slowly moving GPS satellites inclined at $55^{\circ}$. Data from swiftly moving low orbiters in highly inclined orbits will strengthen the $\mathrm{z}$ solution and help close the accuracy gap with $\mathrm{x}$ and $\mathrm{y}$.

\section{THE FUTURE: GLOBAL, REAL- TIME, HIGH-PRECISION, GPS-BASED POSITIONING SYSTEMS}

GPS is now used extensively for orbit determination by scientific and other earth satellites, and for many other science, government, and commercial purposes around the world. GPS currently provides RTK positioning at the level of several meters, with the accuracy depending primarily on the accuracy of the broadcast GPS ephemerides and clocks, and on the quality of the observables in the user's receiver. The majority of GPS users will be well served by the present system, or by widely available commercial DGPS systems, which can provide moderate improvements in real-time accuracy over prescribed local regions, perhaps to the level of one to a few meters. However, a subset of users will continue to seek something more, both in geographical coverage and in positioning accuracy.

The worldwide (global) commercial market for precise real-time location devices, such as handheld or in moving vehicles, is enormous. A triagency effort-involving NASA, NOAA, and DoD-to develop a new generation of operational weather satellites is considering instruments that will require real-time position knowledge to a few decimeters. In addition, various proposed free-flying space missions-including microwave and laser altimeters, synthetic aperture radar (SAR) mappers, and multispectral imagers - are seeking orbit accuracies ranging from centimeters to one meter. While for many this performance is not needed in real time, the ability to 
Navigation, Journ. of the Inst. of Navigation, Vol. 49(1), 7-34, Spring 2002

achieve such accuracy autonomously onboard could save greatly in the cost of ground operations.

Many GPS science applications utilize terrestrial vehicles rather than earth orbiters. SAR imaging, topographic mapping, gravimetry, and other forms of remote and in situ sensing are carried out with balloons, aircraft, ships, buoys, and other vehicles. One of the most stringent goals comes from airborne SAR investigators, who wish to control aircraft flight paths in real time to at least a meter, and eventually to a few centimeters. Comparable goals apply to RTK geodesy, which could be much simplified and readily extended to remote locations with global subdecimeter positioning. A variety of mobile science instruments worldwide could generate finished products in real time, ready for interpretation, with significant savings in data transmission and analysis costs. The scientific appeal of seamless worldwide positioning offering precise postprocessing performance in real time can hardly be overstated.

Table 1 lists some key categories of performance for real-time positioning with GPS. This discussion focuses on submeter positioning. The essential elements of a global-precision WADGPS are first discussed. The remainder of the paper then explores means for obtaining the precise WADGPS performance globally in real time, and without differential corrections, from a proposed extended global realtime GPS tracking system.

Table 1. GPS Performance Requirements

\begin{tabular}{|l|l|l|}
\hline $\begin{array}{c}\text { Accuracy } \\
\text { required, } \\
\text { real-time }\end{array}$ & Technique & Users and Applications \\
\hline $\begin{array}{l}10 \mathrm{~m}- \\
1000 \mathrm{~m}\end{array}$ & $\begin{array}{l}\text { GPS, post- } \\
\text { processed, } \\
\text { predicted to } \\
\text { real time }\end{array}$ & $\begin{array}{l}\text { Satellite routine naviga- } \\
\text { tion and stationkeeping }\end{array}$ \\
\hline $1 \mathrm{~m}-5 \mathrm{~m}$ & $\begin{array}{l}\text { RTK; GPS; } \\
\text { WADGPS }\end{array}$ & $\begin{array}{l}\text { Precise satellite naviga- } \\
\text { tion; surveys; } \\
\text { aircraft navigation; mili- } \\
\text { tary }\end{array}$ \\
\hline$<10 \mathrm{~cm}$ & $\begin{array}{l}\text { Precision } \\
\text { global } \\
\text { WADGPS }\end{array}$ & $\begin{array}{l}\text { High-precision satellite } \\
\text { navigation; geodesy; } \\
\text { high-precision surveys; } \\
\text { aircraft takeoff and land- } \\
\text { ing navigation; SAR, } \\
\text { and precise earth map- } \\
\text { ping }\end{array}$ \\
\hline
\end{tabular}

\section{WADGPS PERFORMANCE}

Commercial WADGPS systems are now providing services nearly worldwide. Meanwhile, the U.S. WAAS - a particularly ambitious example of
WADGPS - is moving towards initial operation to support a several-meter level of accuracy for general aviation navigation over the United States [153]. Similar efforts are being planned in Europe, Asia, and other locations. As noted above, a class of prospective users-from satellites to aircraft to surface vehicles-is emerging that will benefit from realtime positioning accuracies, well surpassing what today's systems can deliver. This is an opportune time to evaluate future interests in precise real-time orbit determination and positioning, taking into account the diversity of applications, performance requirements, utility of current systems, alternative design options, and relevant technologies that can now be brought to bear.

\section{POTENTIAL OF GLOBAL WADGPS}

Many GPS users require global coverage and the highest possible accuracy. Single frequency WADGPS systems do not meet these requirements. In contrast, with a dual frequency system, greater accuracy is achievable and fewer reference sites are needed $[154,155]$. This section discusses the issues of accuracy and global coverage.

To provide global coverage, experiments were designed to take advantage of NASA's GGN, which is operated and maintained by JPL. The GGN consists of approximately 50 sites that are mostly operated in batch mode over the Internet (http://igscb.jpl.nasa.gov). To return data in real time a new software set called Real-Time Net Transfer was developed [156]. One-Hz phase and range observables are returned over the open Internet using User Datagram Protocol. More than $98 \%$ of the data is returned in less than $2 \mathrm{~s}$. Currently 18 global sites are returning data in real time to JPL. Additional sites are being added. These new sites will increase the accuracy of the orbits and clocks, and also system reliability by having redundant receivers in the reference network. To address the issue of accuracy, the system has been optimized for dual-frequency users. Both range and phase dual-frequency observables are used from geodetic reference receivers. The user's software uses the phase observable, not to smooth the range data, but as a basic data type in the user's positioning filter, whose states include, along with the user's position and clock, the necessary phase biases and an optional slowly varying zenith troposphere parameter. (Also see POSITIONING section) Tests in early 2000 of user positions show real-time, $8-\mathrm{cm}$ RMS accuracy in the horizontal component and 20$\mathrm{cm}$ RMS accuracy in the vertical component [156]. These test results are for kinematic real-time user positioning on the ground. The user could be in principle moving on the ground or airborne, and the 
accuracy should be similar (an airborne user might experience a small improvement in accuracy from elimination of some tropospheric effects) virtually anywhere in the world. To achieve these breakthrough results, GPS orbits had to be generated in real time, accurate to $30-40 \mathrm{~cm}$. Such positioning results are about an order of magnitude better than typically available from either the broadcast ephemeris or from commercial DGPS providers.

In order to achieve GPS-based, high-accuracy (10-cm level) positioning in real time for terrestrial users that are situated below the atmosphere, one must develop a methodology for determining troposphere path delays to the $1-\mathrm{cm}$ level. This, in fact, has now been demonstrated [156, 157], which places the responsibility for exploiting this rich data set firmly in the hands of the meteorologists. The advancement of large-scale dense networks of GPS receivers-including several that are operating in Japan, SCIGN and, most recently, Suominet-has the potential to significantly augment existing sparse radiosonde networks and provide meteorologists with enhanced observations of atmospheric water vapor $[158,159]$ to improve weather forecasting and enable detailed studies of climate and hydrology. The development and deployment of such networks of receivers contributing to these applications is a dramatic example of enabling science through technology advances.

For real-time onboard positioning and orbit determination a satellite would require flight software with the necessary orbit models, estimator, and propagator. A version of such software can be embedded in an onboard GPS receiver or processor to support this capability. For high-precision, realtime positioning in space, the availability of a global DGPS system is essential, as the spaceborne user requires global coverage. Local or regional systems (such as WAAS or various commercial systems) do not provide global coverage.

A new era of GPS-based positioning for highprecision GPS users has been entered, either in LEO or in near-earth and/or ground applications. As discussed above, a demonstration has shown that ground user positioning can potentially be achieved with a global wide-area differential system at the level of $8 \mathrm{~cm}$ (horizontal) to $20 \mathrm{~cm}$ (vertical) in real time. For this demonstration, inexpensive Internet links were used for data communications. In earth orbit, such kinematic capability would translate into $5-\mathrm{cm}$ accuracy for real-time orbit accuracies at $1300-\mathrm{km}$ altitude, and about $10-\mathrm{cm}$ orbit accuracies (real time) at $500-\mathrm{km}$ altitude, for which Kalman filtering can be employed.

Real-time GPS accuracy is catching up to nonreal time GPS accuracy through recent dramatic ad- vances in global WADGPS. This accuracy improvement will soon change the entire character of GPS applications, ranging from commercial, to scientific, to military. It is only fitting that this remarkable change in the GPS landscape was achieved for the first time using the Internet, which has itself often been blamed for the apparent acceleration of the pace of life in general and of data communications, resulting in a sort of compression of the world. Real-time user positioning on the ground and in space will probably be ultimately limited by GPS signal noise, user equipment noise, and multipath. For orbiting users, the quality of dynamic models and multipath are likely to limit the accuracies achievable. Obviously, dynamic models are worse for lower altitudes, but at this time, it is not clear where these errors will eventually cause performance to bottom out. It is possible that within the coming decade, ground, airborne, and space users will routinely have knowledge of position to several centimeters in real time. One thing has been clear: based on past history, GPS researchers can be expected to continue to surpass even the most aggressive future projections for accuracy and performance.

\section{CONCLUSION}

Developments in GPS geodesy have been fundamental to many of the improvements in GPS over the past decades. Geodesy has set the highest accuracy requirements and has motivated many of the enhancements to both equipment and software. These improvements allowed the GPS user to enjoy the advantages of more accurate measurements and processing, orbit determination, tracking site positioning, and WGS 84 reference frame definition.

Three generations of improved geodetic receivers provided the basic tools to allow GPS geodesy and software developments to flourish. In addition to the standard pseudorange measurement, dualfrequency receivers provided the very accurate integrated carrier-phase measurement, with all measurements synchronized to occur at prescribed GPS times. These measurements were applied through sophisticated techniques to achieve positioning accuracy well beyond the capabilities of the pre-GPS era.

Improved positioning and timing accuracy was accomplished incrementally. Concurrent to equipment improvement was a better understanding of the measurements and their associated errors. Initial capabilities for short-baseline static and kinematic surveying were extended to long baselines and then global networks. Simultaneously, orbit determination continuously improved, reducing satellite position errors several orders of magnitude from the early years. 
Improved models of polar motion, tectonic plate motion, and earth tides aided this development. Geodynamic analyses motivated continued efforts in this area.

During the last three decades, the geodetic community has enjoyed a spirit of cooperation, which underlies the successes it has achieved. This spirit of cooperation started in the initial years (when equipment, high-quality measurement data and locations with a sufficient number of satellites to track were not readily available) and continues. Indeed, it is required to meet the global networking needs for the ongoing geodynamic, atmospheric, and earth modeling activities.

The impact of the geodetic enhancements to GPS has been far-reaching. Every user has benefited from the impacts to operational GPS. Computational techniques and software developments of the geodetic community have been incorporated into many GPS applications to produce new user capabilities. Accuracy enhancements, especially to point positioning, can be expected to continue well into the future along with the implementation of operational and real-time geodetic initiatives.

\section{ACKNOWLEDGMENTS}

The authors and the geodetic community are indebted to the many individuals who have contributed to satellite geodesy and to GPS. The authors wish to acknowledge the many contributors who have not been referenced in this paper or in the literature. Mr. Gaylord Green, as Chair of the Institute of Navigation Satellite Division Executive Committee, requested that this historical paper on GPS geodesy be written and suggested the title at the September 1998 meeting. In addition, the authors wish to recognize other individuals who have reviewed or provided assistance with the paper. These include Dr. Gerard Lachapelle of the University of Calgary, Dr. Walter Senus of the NIMA, and Ms. Patrice Waits, Dr. Bruce Hermann, Dr. Jeffrey Blanton, Dr. John Wedding, and Dr. John Lundberg of NSWCDD.

\section{REFERENCES}

1. Bowditch, Nathaniel, "American Practical Navigator," An Epitome of Navigation, 1977 edition, published by Defense Mapping Agency, p. 1296, 1977.

2. Hotine, Martin, "Mathematical Geodesy," Published by Environmental Science Services Administration, preface p. ix, 1969.
3. ___ "A Scientific Satellite Program," prepared by Rocket Development Branch, Atmosphere and Astrophysics Division, Naval Research Laboratory, pp. 8-11, April 13, 1955.

4. O'Keefe, John A.; Eckels, Ann; and Squires, R. Kenneth, "The Gravitational Field of the Earth," The Astronomical Journal, Vol. 64, No. 7, pp. 245-253, September 1959.

5. Mickielsen, Herman F., "Fifth Harmonic of the Earth's Gravitational Field," American Rocket Society Journal, p. 976, October 1960.

6. King-Hele, D.G., "Evaluation of the Second, Fourth and Sixth Harmonics in the Earth's Gravitational Potential," Nature, Vol. 187, p. 490, August 6, 1960.

7. Guier, W.H. and Weiffenbach, G.C., "A Satellite Doppler Navigation System," Proceedings of the Institute of Radio Engineers, Vol. 48, No. 4, pp. 507516, April 1960.

8. Anderle, Richard J., "Geodesy for the Navy Navigation Satellite System," keynote address, Proceedings of the Third International .Geodetic Symposium on Satellite Doppler Positioning, Vol. 1, p. 4, February 8, 1982.

9. Kouba, J. and Hothem, L.D., "Doppler Results On Federal Geodetic Control Committee (FGCC) Test Net," Proceedings of the Fourth International Geodetic Symposium on Satellite Positioning, Vol. 2, p. 889, April 28, 1982.

10. Spilker, Jr., J.J., "GPS Signal Structure and Performance," Global Positioning System, papers published in Navigation, Vol. I, 1980.

11. Parkinson, B.W.; Spilker, Jr., J.J.; Axelrad, P.; and Enge, P. (eds.), "Global Positioning System: Theory and Applications," Progress in Astronautics and Aeronautics, Vol. 164, American Institute of Aeronautics and Astronautics, Inc., 1996.

12. Hermann, B.R., "Formulation for the NAVSTAR Geodetic Receiver System (NGRS)," Naval Surface Weapons Center Technical Report 80-348, March 1981.

13. Senus, W.J. and Hill, R.W., "GPS Application to Mapping, Charting, and Geodesy," Navigation, Vol. 30, No. 2, p. 157, April 1981.

14. Hill, R.W. and Senus, W.J. "The Development of a Navstar Geodetic Receiver," Proceedings of IEEE Plans 82 Position Location and Navigation Symposium, p. 339, December 1982.

15. Roth, Ben and Renfroe, Brent, "The DMA GPS Tracking Network," Proceedings of the 44th Annual Meeting of the Institute of Navigation, p. 487, June 1993.

16. Van Dierendonck, A.J.; Melton, W.C.; Birnbaum, M.; and Harkins, M.D., "The Approach to Satellite Ephemeris Determination for the NAVSTAR Global Positioning System," Navigation, Vol. 23, No. 1, p. 76086, Spring 1976. 
17. Fliegel, H.F.; Feess, W.A.; Layton, W.C.; and Rhodus, N.W., "The GPS Radiation Force Model," Proceedings of the First International Symposium on Precise Positioning with the Global Positioning System, National Geodetic Survey, NOAA, Rockville, MD, pp. 113-119, 1985.

18. Schaibly, J.H. and Harkins, M.D., "The NAVSTAR Global Positioning System Control Segment Performance During 1978," Proceedings of the Second International Geodetic Symposium on Satellite Doppler Positioning, Austin, TX, pp. 1175-1192, January 22-26, 1979.

19. Bowen, Lt. Col. R; Swanson, P.L.; Winn, F.B.; Rhodus, N.W.; and Feess, W.A., "Global Positioning System Operational Control System Accuracies," Navigation, Vol. 32, No. 2, Summer 1985.

20. Francisco, S., "Chapter 10. GPS Operational Control Segment," Global Positioning System: Theory and Applications, Vol. 1, pp. 435-466, AIAA, Washington, DC, 1996.

21. Satin, A.L.; Feess, W.A.; and Merritt, B.D., "A Comparison of Global Positioning System Control Segment Performance Using Simulated Data," Proceedings of the AAS/AIAA Astrodynamics Specialist Conference, Vail, Colorado, August 12-15, 1985.

22. Feess, B.; Iroz, J.; Satin, A.; Winn, B.; Wiseman, C.; Hermann, B.; Swift, E.; Beisner, H.; Allan, D.; Davies, D.; Weiss, M.; Klepczynski, W.; and Withington, F., "GPS Satellite-to-User Range Accuracies: A Calibration Experiment," Navigation, Vol. 34, No. 3, Fall 1987.

23. Fliegel, H.F. and Gallini, T.E., "Radiation Pressure Models for Block II GPS Satellites," Proceedings of Fifth International. Geodetic Symposium on Satellite Positioning, Las Cruces, NM, March 13-17, 1989.

24. Fliegel, H.; Swift, E.; and Gallini, T., "Global Positioning System Radiation Force Model for Geodetic Applications," Journal of Geophysical Research, Vol. 97, No. B1, pp. 559-568, January 10, 1992.

25. Scardera, Capt. M.P., "The NAVSTAR GPS Master Control Station's Kalman Filter Experience," Flight Mechanics/Estimation Theory Symposium 1990, NASA Conference Proceedings CP3102, 1991.

26. Brown, K.R., "The Theory of the GPS Composite Clock," Proceedings of ION GPS-91, Albuquerque, NM, pp. 223-241, September 11-13, 1991.

27. Zumberge, J.F. and Bertiger, W.I., "Chapter 16. Ephemeris and Clock Navigation Message Accuracy," Global Positioning System: Theory and Applications, Vol. 1, AIAA, Washington, DC, pp. 585-599, 1996.

28. Hutsell, Capt. S.T., "Fine Tuning GPS Clock Estimation in the MCS," Proceedings of PTTI-94, Reston, VA, December 1994.
29. Crum, J.D.; Hutsell, S.T.; and Smetek, R.T., "The 2SOPS Ephemeris Enhancement Endeavor (EEE)," Proceedings of PTTI-97, Long Beach, CA, December 2-4, 1997.

30. Conley, R., "Results of the GPS JPO's GPS Performance Baseline Analysis: The GOSPAR Project," Proceedings of ION GPS-97, Kansas City, MO, September 1997.

31. Shaw, M.; Sandhoo, K.; and Turner, D., "Modernization of the Global Positioning System," GPS World, pp. 36-44, September 2000.

32. McDonald, K.D., and Hegarty, C., "PostModernization GPS Performance Capabilities," Proceedings of the IAIN World Congress and the Institute of Navigation $56^{\text {th }}$ Annual Meeting, San Diego, CA, June 26-28, 2000.

33. Malys, S.; Larezos, M.; Gottschalk, S.; Mobbs, S.; Winn, B.; Feess, W.; Menn, M.; Swift, E.; Merrigan, M.; and Mathon, W., "The GPS Accuracy Improvement Initiative," Proceedings of ION GPS-97, Kansas City, MO, September 16-19, 1997.

34. Carr, J.T. and O'Toole, J. W., "Point Positioning with the NAVSTAR Global Positioning System," Proceedings of PLANS 1982, San Diego, CA, December 1982.

35. Heuerman, H. P., "Global Positioning System Geodetic Tracking Program," Proceedings of the Third International Geodetic Symposium on Satellite Doppler Positioning, Vol. 2, Las Cruces, NM, pp. 1041-1056, February 8-12, 1982.

36. Swift, E., "NSWC's GPS Orbit/Clock Determination System," Proceedings of the First International Symposium on Precise Positioning with GPS, Rockville, MD, April 15-19, 1985.

37. Swift, E., Mathematical Description of the GPS Multisatellite Filter/Smoother, NSWC TR 87-187, October 1987.

38. Swift, E. and Gouldman, W., "Preliminary Evaluation of GPS Orbit/Clock Determination Accuracy," Manuscripta Geodaetica, Vol. 14, pp. 125-132, 1989.

39. Swift, E. and Hermann, B., "Orbit Period Frequency Variations in the GPS Satellite Clocks," Proceedings of PTTI Meeting, Vienna, VA, November 29December 1, 1988.

40. Swift, E., "Reducing the Effects of Eclipsing on the GPS Precise Ephemeris and Clock Quality," Proceedings of the Second International Symposium on Precise Positioning with the Global Positioning System, Ottawa, Canada, September 3-7, 1990.

41. Swift, E., "GPS Orbit/Clock Estimation Based on Smoothed Pseudorange Data from a Ten-Station Global Network," Presented at the IUGG General Assembly IAG Symposium G-2, Permanent Tracking Networks for Geodesy and Geodynamics, Vienna, Austria, August 16, 1991. Later published in 
Proceedings of IAG Symposium 109, SpringerVerlag, pp. 151-160, 1992.

42. McCarthy, D.D. (ed.), IERS Standards (1992), IERS Technical Note 13, Observatoire de Paris, July 1992.

43. Cunningham, J.; Swift, E.; and Mueller, F, "Improvement of the NIMA Precise Orbit and Clock Estimates," Proceedings of ION GPS-98, Nashville, TN, September 15-18, 1998.

44. National Imagery and Mapping Agency, Department of Defense World Geodetic System 1984, NIMA TR8350.2 Third Edition Amendment 1, January 3, 2000.

45. Department of Defense World Geodetic System 1984: Its Definition and Relationships with Local Geodetic Systems, NIMA TR8350.1, 3rd Ed., July 4, 1997.

46. Swift, E., "Improved WGS 84 Coordinates for the DMA and Air Force GPS Tracking Sites," Proceedings of ION GPS-94, Salt Lake City, UT, September 20-23, 1994.

47. Cunningham, J. and Curtis, V., WGS 84 Coordinate Validation and Improvement for the NIMA and Air Force GPS Tracking Stations, NSWCDD/TR96/201, Dahlgren, VA, November 1996.

48. Meyerhoff, S., Error Statistics from Predicting UT1-UTC and Pole Position, NSWC/DL TR-3859, Dahlgren, VA, August 1978.

49. Bangert, J., "The DMA/GPS Earth Orientation Prediction Service," Proceedings of the $4^{\text {th }}$ Intl. Geodetic Symposium on Satellite Positioning, pp. 151164, Austin, TX, 1986.

50. Swift, E., "Comparison of GPS-Derived Earth Orientation Parameters with Final BIH/IERS and USNO Values," Proceedings of the $5^{\text {th }}$ International Geodetic Symposium on Satellite Positioning, Las Cruces, NM, March 13-17, 1989.

51. Funk, T.J. and Lafler, M., Desert Storm Surveying, P.O.B. (Point of Beginning), Vol. 17, No. 1, October-November 1991.

52. Braasch, Michael S., "A Signal Model for GPS," Navigation, Winter 1990-1991, Vol. 37, No. 4.

53. Melbourne, William G., "The Case for Ranging in GPS-Based Geodetic Systems," Proceedings of the First International Symposium on Precise Positioning with the Global Positioning System, Rockville, MD, April 15-19, 1985.

54. Hermann, B.R. and Malys, S., "Precise Absolute Navigation: An Evaluation of PPS Position Improvement," Institute of Navigation, ION-GPS-95, Palm Springs, CA, September 1995.

55. Brown, J.; Cannon, M.E.; and Roberts, D., "Comparison of Methods for Obtaining Absolute WGS 84 Position in Remote Locations," Proceedings of ION GPS-94, Salt Lake City, UT, 1994.

56. Henriksen, J.; Lachapelle, G.; Raquet, J.; and Stephen, J., "Analysis of Stand-Alone GPS Position- ing Using Post-Mission Information," Proceedings of ION GPS-96, Institute of Navigation, Kansas City, MO, 1996, pp. 251-259.

57. Hermann, B.R., "Five Years of Absolute Positions at the Naval Surface Warfare Center," The Sixth International Geodetic Symposium on Satellite Positioning, Columbus, OH, March 1992.

58. Lachapelle, G. and Beck, N., "NAVSTAR/GPS Single Point Positioning at Sheltech CanadaPreliminary Results," Presented at the European Geophysical Society Meeting, Uppsala, Sweden, The Canadian Surveyor, Vol. 36, No. 1., pp. 29-42, August 1982.

59. Malys, S.; Bredthauer, D.; Hermann, B.; and Clynch, J., "Geodetic Point Positioning with GPS: A Comparative Evaluation of Methods and Results," Proceedings of the Sixth International Symposium on Satellite Positioning, Ohio State University, Columbus, OH, March 1992.

60. Malys, S.; Bredthauer, D.; and Deweese, S., "Error Budget for the DMA GPS Geodetic Point Positioning Algorithm Through Monte Carlo Simulation," Institute of Navigation, ION-GPS-93 Salt Lake City, UT, September 1993.

61. McBurney, P. and Neumann, J., "Highly Accurate Point Positioning and Time Transfer Using a StandAlone GPS Receiver," Stanford Telecom, STel-TR89494, September 1989.

62. Meyer, T.E.; Tennis, G.T.; Slater, J.A.; and DeNoyer, B.J., "DMAHTC GPS Point Positioning Software: Initial Results," Proceeding of the Fourth International Geodetic Symposium on Satellite Positioning, Austin, TX, May 1986.

63. Zumberge, J.F.; Heflin, M.B.; Jefferson, D.C; Watkins, M.M.; and Webb, F.H., "Precise Point Positioning for the Efficient and Robust Analysis of GPS Data From Large Networks," Journal of Geophysical Research, Vol. 102, No. B3, pp. 50055017, March 10,1997.

64. Gabor, M.J. and Nerem, R.S., "GPS Carrier Phase Ambiguity Resolution Using Satellite-Satellite Single Differences," Institute of Navigation GPS-99, Nashville, TN, September 14-17, 1999.

65. Hatch, R.R. and Larson, K., "Magnet-4100 GPS Survey Program Processing Techniques and Test Results," Proceedings of the First International Geodetic Symposium on Precise Positioning with the Global Positioning System, Rockville, MD, April 1985.

66. Kalafus, R.M. et al., "Differential Operation of NAVSTAR GPS," Navigation, Vol. 30, No. 3, pp. 187-204, Fall 1983.

67. Sennott, J.W. and Pietraszewski, D., "Experimental Measurement and Characterization of Ionospheric and Multipath Errors in Differential GPS," Navigation, Vol. 34, No. 2, pp. 160-173, Summer 1987. 
68. Pietraszewski et al., "U.S. Coast Guard Differential GPS Navigation Field Test Findings," Navigation, Vol. 35, No. 1, pp. 55-72, Spring 1988.

69. Loomis, P. et al., "Correction Algorithms for Differential GPS Reference Stations," Navigation, Vol. 36, No. 2, pp. 179-194, Summer 1989.

70. Evans, A.G.; Hermann, B.W.; and Fell, P.J., "Global Positioning System Sensitivity Experiment," Navigation, Vol. 28, No. 2, pp. 74-84, Summer 1981.

71. Greenspan, R.L., Ng, A.Y., Przyjemski, J.M., and Veale, J.D., "Accuracy of Positioning by Interferometry with Reconstructed Carrier GPS: Experimental Results," Proceedings of the Third International Symposium on Satellite Positioning, New Mexico State University, Las Cruces, New Mexico, February 1982.

72. Hatch, R., "Dynamic Differential GPS at the Centimeter Level," Proceedings of the Fourth International Symposium on Satellite Positioning, University of Texas, Austin, April 1986.

73. Mader, G.L., "Decimeter Level Aircraft Positioning Using GPS Carrier Phase Measurements," Proceedings of the Fourth International Geodetic Symposium on Satellite Positioning, Austin, Texas, April 1986.

74. Goad, C., "Optimal Filtering of Pseudoranges and Phases from Single Frequency GPS Receivers," Navigation, Vol. 37, No. 3, pp. 249-262, Fall 1990.

75. Hwang, P., "Kinematic GPS for Differential Positioning: Resolving Integer Ambiguities on the Fly," Navigation, Vol. 38, No. 1, pp. 1-15, Spring 1991.

76. Teunissen, P.J.G., "The Least-Squares Ambiguity Decorrelation Adjustment: A Method for Fast GPS Integer Ambiguity Estimation," Journal of Geodesy, Vol. 1, No. 2, pp. 65-82, 1995.

77. Hatch, R.; Jung, J.; Enge, P.; and Pervan, B., "Civilian GPS: The Benefits of Three Frequencies," GPS Solutions, Vol. 3, No. 4, pp. 1-9, 2000.

78. Vollath, U.; Buecherl, A.; Landau, H.; Pagels, C.; and Wagner, B. "Multi-Based RTK Positioning Using Virtual Reference Stations," Institute of Navigation GPS-2000, Salt Lake City, UT, September 19$22,2000$.

79. Gao, Y.; Li, Z.; and McLellan, J., "Carrier Phase Based Regional Area Differential GPS for Decimeter-Level Positioning and Navigation," Institute of Navigation GPS-96, Kansas City, MO, September 17-20, 1996.

80. Raquet, J. and Lachapelle, G., "Development and Testing of a Kinematic Carrier-Phase Ambiguity Resolution Method Using a Reference Receiver Network," Navigation, The Journal of the Institute of Navigation, Alexandria, VA, Vol. 46, No. 4, pp. 283-29, Winter 1999-2000.
81. van der Marel, H. "Virtual GPS Reference Stations in the Netherlands," Institute of Navigation GPS-98, Nashville, TN, September 15-18, 1998.

82. Vollath, U.; Buecherl, A.; Landau, H.; Pagels, C.; and Wagner, B. "Long-Range RTK Positioning Using Virtual Reference Stations," Institute of Navigation GPS-2000, Salt Lake City, UT, September 1922, 2000.

83. Colombo, O., "Long-Distance Kinematic GPS," Chapter 13 of GPS for Geodesy, $2^{\text {nd }}$ ed., SpringerVerlag, New York, 1998.

84. Colombo, O. and Evans, A., "Testing DecimeterLevel Kinematic, Differential GPS Over Great Distances at Sea and on Land," Proceedings of the Satellite Division of the Institute of Navigation, ION GPS-1998, September 1998.

85. National Research Council, National Academy of Sciences, "The Global Positioning System, A Shared National Asset," National Academy Press, Washington, DC, 1995.

86. National Research Council, National Academy of Sciences, "Toward a Coordinated Spatial Data Infrastructure for the Nation," National Academy Press, Washington, DC, 1993.

87. Segall, P. and Davis, J.L., "GPS applications for Geodynamics and Earthquake Studies, Annual Review of Earth and Planetary Sciences, Vol. 25, pp. 301-336, 1997.

88. Rogers, A.E.E.; Knight, C.A.; Hinteregger, H.F.; Whitney, A.R.; Counselman, C.C.; Gourevitch, S.A.; and Clark, T.A., "Geodesy by Radio Interferometry: Determination of a 1.24-km Base Line Vector with 5-mm Repeatability," Journ. Geophys. Res., Vol. 83, pp. 325-334, 1978.

89. MacDoran, P.F., "Satellite Emission Radio Interferometric Earth Surveying SERIES-GPS Geodetic System," Bulletin Geodesique, Vol. 53, pp. 117138, 1979.

90. Counselman, C.C. and Shapiro, I.I., "Miniature Interferometer Terminals for Earth Surveying," Bulletin Geodesique, Vol. 53, No. 2., pp. 139-163, 1979.

91. Counselman, C.C.; Abbot, R.I.; Gourevitch, S.A.; King, R.W.; and Paradis, A.R., "Centimeter-Level Relative Positioning with GPS," Journ. Surv. Eng., pp. 81-89, 1983.

92. Counselman, C.C.; Hinteregger, H.F.; and Shapiro, I.I., "Astronomical Applications of Differential Interferometry," Science, Vol. 178, pp. 607-608, 1972.

93. Wu, J.T., "Estimation of Clock Errors in a GPS Based Tracking System," in Proceedings of the AIAA/AAS Astrodynamics Conference, Seattle, WA, 1984.

94. Smith D.E. and Turcotte, D.L. (eds.), "Contributions of Space Geodesy to Geodynamics: Technology," Geodynamics Series, Vol. 25, American Geophysi- 
cal Union, Washington, DC, ISBN 0-87590-526-9, 213 pp., 1993.

95. Gurtner, W.; Beutler, G.; Bauersima, I.; and Schildknecht, T., "Evaluation of the GPS Carrier Phase Difference Observations: The BERNESE Second Generation Software Package," in Proceedings of the First International Symposium on Precise Positioning with the Global Positioning System, Goad C., (Ed.), U.S. Dept. of Commerce, Rockville, MD, 1985.

96. Bock, Y.; Abbot, R.I.; Gourevitch, S.A.; and King, R.W., "Establishment of Three-Dimensional Geodetic Control by Interferometry with the Global Positioning System,” Journ. Geophys. Res., Vol. 90, 1985.

97. Lichten, S.L. and Border, J.S., "Strategies for HighPrecision Global Positioning System Orbit Determination," Journ. Geophys. Res., Vol. 92, pp. 12,75112,762, 1987.

98. Davidson, J.M.; Thornton, C.L.; Vegos, C.J.; Young, L.E.; and Yunck, T.P., "The March 1985 Demonstration of the Fiducial Network for GPS Geodesy: A Preliminary Report," in Proceedings of the First International Symposium on Precise Positioning with the Global Positioning System, Goad C., (Ed.), U.S. Dept. of Commerce, Rockville, MD, pp. 603-612, 1985.

99. Tralli, D.M.; Dixon, T.H.; and Stephens, S.A., "The Effect of Wet Troposphere Path Delays on Estimation of Geodetic Baselines in the Gulf of California Using the Global Positioning System," Journ. Geophys. Res., pp. 6,545-6,557, 1988.

100. Murray, M.H.; Bock, Y.; Dong, D.N.; Feigl, K.L.; Jordan, T.H.; and King, R.W., "Assessing the LongTerm Repeatability and Accuracy of GPS: Analysis of Four Campaigns in California," EOS. Trans. Am. Geophys. U., Vol. 69, p. 1151, 1988.

101. Prescott, W.H.; Davis, J.L.; and Svarc, J.L., "Global Positioning System Measurements for Crustal Deformation: Precision and Accuracy," Science, Vol. 244, pp. 1,337-1,340, 1989.

102. Dong, D. and Bock, Y., "GPS Network Analysis with Phase Ambiguity Resolution Applied to Crustal Deformation Studies in California," Journ. Geophys. Res., Vol. 94, pp. 3,949-3,966, 1989.

103. Blewitt, G., "Carrier Phase Ambiguity Resolution for the Global Positioning System Applied to Geodetic Baselines up to $2000 \mathrm{~km}$," Journ. Geophys. Res., Vol. 94, pp. 10,187-10,283, 1989.

104. Counselman, C.C. and Abbot, R.I., "Method of Resolving Radio Phase Ambiguity in Satellite Orbit Determination," Journ. Geophys. Res., Vol. 94, pp. 7,058-7064, 1989.

105. Blewitt, G. and Lichten, S.L., "Carrier Phase Ambiguity Resolution up to $12,000 \mathrm{~km}$ : Results From the GIG'91 Experiment," in Proceedings of the Sixth
International Symposium on Satellite Positioning, Columbus, Ohio State University, 1992.

106. Neill, A.E., "Global Mapping Functions for the Atmosphere Delay at Radio Wavelengths," Journ. Geophys. Res., Vol. 101, pp. 3,227-3,246, 1996.

107. Chen, G. and Herring, T.A., "Effects of Atmospheric Azimuthal Asymmetry on the Analysis of Space Geodetic Data," Journ. Geophys. Res., Vol. 102, pp. 20,489-20,502, 1997.

108. Bar Sever, Y.E.; Kroger, P.M.; and Borjesson, J.A., "Estimating Horizontal Gradients of Tropospheric Path Delay With a Single GPS Receiver," Journ. Geophys. Res., Vol. 103, pp. 5019-5035, 1998.

109. Srinivasan, J.M.; Meehan, T.K.; and Young, L.E., "Code and Codeless Ionospheric Measurements With NASA's Rogue GPS Receiver,' in Proceedings of the Institute of Navigation, GPS-89 Conf., Institute of Navigation, pp. 451-454, 1989.

110. McCarthy, D., IERS Technical Note 21-IERS Conventions, IERS Central Bureau, Observatoire de Paris, 1996.

111. Beutler G.; Kouba J.; and Springer, T., "Combining the Orbits of the IGS Analysis Centers," Bulletin Geodesique, Vol. 69, pp. 200-222, 1995.

112. Davies, P.H. and Blewitt, G., "Methodology for Global Geodetic Time Series Estimation: A New Tool for Geodynamics," Journ. Geophys. Res., Vol. 105, No. B5, pp. 11,083-11,100, 2000.

113. Mueller, I.I., "Satellite Positioning and the IAG," in Proceedings of the Second International Symposium on Precise Positioning with GPS, Canadian Institute of Surveying and Mapping, Ottawa, Canada, pp. xiviii-lxvi, 1990.

114. Larson, K.M. and Freymueller, J., "Relative Motion of the Australian, Pacific, and Antarctic Plates Estimated by the Global Positioning System," Geophys. Res. Lett., Vol. 22, pp. 37-40, 1995.

115. Argus, D.F. and Heflin, M.B., "Plate Motion and Crustal Deformation Estimated With Geodetic Data From the Global Positioning System," Geophys. Res. Lett., Vol. 22, pp. 1973-1976, 1995.

116. Bock, Y.; Agnew, D.C.; Fang, P.; Genrich, J.F.; Hager, B.H.; Herring, T.A.; King, R.W.; Larsen, S.; Minster, J.B.; Stark, K.; Wdowinski, S.; and Wyatt, F., "Detection of Crustal Deformation From the Landers Earthquake Sequence Using Continuous Geodetic Measurements," Nature, Vol. 361, pp. 338-340, 1993.

117. Blewitt, G.; Heflin, M.B.; Hurst, K.J.; Jefferson, D.C.; Webb, F.H.; and Zumberge, J.F., "Absolute Far-Field Displacements from the June 28, 1992 Landers Earthquake Sequence," Nature, Vol. 361, pp. 340-342, 1993.

118. Gurtner, W. and Mader, G., "Receiver Independent Exchange Format Version 2," Bulletin of the International Coordination of Space Techniques for Ge- 
odesy and Geodynamics, CSTG GPS Subcommission and U.S. Department of Commerce, Vol. 3, No. 3, pp. 1-8, September-October 1990.

119. Evans, A., "Summary of the Workshop on GPS Exchange Formats," Proceedings of the Fifth International Geodetic Symposium on Satellite Positioning, Las Cruces, NM, March 13-17, 1989.

120. Ambrosius, B.; Beutler, G.; Blewitt, G.; and Neilan, R., "The Role of GPS in the WEGENER Project," Journ. Geodyn., Vol. 25, pp. 213-240, 1998.

121. Plag, H.P.; Ambrosius, B.; Baker, T.; Beutler, G.; Bianco, G.; Blewitt, G.; Boucher, C.; Davis, J.L.; Degnan, J.J.; Johansson, J.M.; Kahle, H.G.; Kumkova, I.; Marson, I.; Mueller, S.; Pavlis, E.; Pearlman, M.; Richter, B.; Spakman, W.; Tatevian, S.K.; Tomasi, P.; Wilson, P.; and Zerbini, S., "Scientific Objectives of Current and Future WEGENER Activities," Tectonophys., Vol. 294, pp. 177223, 1998.

122. Blewitt, G.; Bock, Y.; and Gendt, G., "Global GPS Network Densification: A Distributed Processing Approach," in Kouba, J. (Ed.), Proceedings of the IGS Analysis Center Workshop, October 12-14, 1993.

123. Segall, P. and Matthews, M., "Time Dependent Inversion of Geodetic Data," Journ. Geophys. Res., Vol. 102, pp. 22,391-22,409, 1997.

124. Herring, T.A., "Sub-Milliarcsecond Determination of Pole Position Using Global Positioning System Data," Geophys. Res. Lett., Vol. 18, pp. 1,8931,896, 1991.

125. Heflin, M.B.; Bertiger, W.I.; Blewitt, G.; Freedman, A.P.; Hurst, K.J.; Licthen, S.M.; Lindqwister, U.J.; Vigue, Y.; Webb, F.H.; Yunck, T.P.; and Zumberge, J.F., "Global Geodesy using GPS without Fiducial Sites,” Geophys. Res., Lett., Vol. 19, pp. 131-134, 1992.

126. Van Dam, T.M.; Blewitt, G.; and Heflin, M.B., "Atmospheric Pressure Loading Effects on Global Positioning System Coordinate Determinations," Journ. Geophys. Res., Vol. 99, pp. 23,939-23,950, 1994.

127. Vigue, Y.; Lichten, S.M.; Blewitt, G.; Heflin, M.B.; and Malla, R.P., "Precise Determination of the Earth Center of Mass Using Measurements from the Global Positioning System," Geophys. Res. Lett., Vol. 19, pp. 1,487-1,490, 1992.

128. Baker, T.F.; Woodworth, P.L.; Blewitt, G.; Boucher, C.; and Woppelmann, G., "A European Network for Sea Level and Coastal Land Level Monitoring," Journ. Marine Systems, Vol. 13, pp. 163-171, 1997.

129. Blewitt, G.; Heflin, M.B.; Webb, F.H.; Lindqwister, U.J.; and Malla, R.P., "Global Coordinates with Centimeter Accuracy in the International Terrestrial Reference Frame using the Global Positioning Sys- tem," Geophys. Res. Lett., Vol. 19, pp. 853-856, 1992.

130. Boucher, C. and Altamimi, Z., "Development of a Conventional Terrestrial Reference Frame," Contributions of Space Geodesy to Geodynamics: Earth Dynamics, Smith D.E. and Turcotte D.L. (eds.), Washington, DC: American Geophysical Union, 1993.

131. Hoffman, E.J. and Birmingham, W.P., "GPSPAC: A Spaceborne GPS Navigation Set," Proceedings of IEEE PLANS '78, pp. 13-20, November 1978.

132. Birmingham, W.P.; Miller, B.L.; and Stein, W.L., "Experimental Results of Using the GPS for Landsat 4 Onboard Navigation," Navigation, The Journal of the Institute of Navigation, Vol. 30, No. 3, pp. 244-251, Fall 1983.

133. Yunck, T.P.; Melbourne, W.G.; and Thornton, C.L., "GPS-Based Satellite Tracking System for Precise Positioning," IEEE Trans. Geosci. and Remote Sensing, GE-23, pp. 450-457, July 1985.

134. Yunck, T.P.; Wu, S.C.; Wu, J.T.; and Thornton, C.L., "Precise Tracking of Remote Sensing Satellites With the Global Positioning System," IEEE Trans. Geosci. \& Remote Sensing, 28, pp. 108-116, 1990.

135. NASA, Solid Earth Science in the 1990s; Volume 2-Panel Reports: NASA Technical Memorandum 4256, v.2, Washington, DC, 1991.

136. Ondrasik, V.J. and Wu, S.C., "A Simple and Economical Tracking System With Sub-Decimeter Earth Satellite and Ground Receiver Position Determination Capabilities," Proceedings of the Third International Symposium on the Use of Artificial Satellites for Geodesy and Geodynamics, Ermioni, Greece, September 1982.

137. Ananda, M.P. and Chernick, M.R., High-Accuracy Orbit Determination of Near-Earth Satellites Using Global Positioning System (GPS), Proceedings of IEEE PLANS '82, Atlantic City, pp. 92-98, December 6-9, 1982.

138. Yunck, T.P., "Orbit Determination," in Global Positioning System-Theory and Applications, B. Parkinson and J. Spilker (eds.), AIAA, Washington, DC, pp. 559-592, 1996.

139. Rosborough, G. and Mitchell, S., "Geographically Correlated Orbit Error for the Topex Satellite Using GPS Tracking," AIAA 90-2956, Proceedings of the AIAA/AAS Astrodynamics Conference, Part 2, Portland, OR, pp. 655-663, August 20-22, 1990.

140. Schutz, B.E.; Tapley, B.D.; Abusali, P.A.M.; and Rim, H.J., "Dynamic Orbit Determination Using GPS Measurements From Topex/Poseidon," Geophys. Res. Lett., 21 (19), pp. 2179-2182, 1994.

141. Muellerschoen, R.; Bertiger, W.; Lough, M.; Dong, D.; and Stowers, D., "An Internet-Based Global Differential GPS System,” initial results, 
Inst. of Navigation 2000 Natl. Technical Meeting, Anaheim, CA, January 2000.

142. LaBrecque, J.; Lowe, S.; Young, L.; Caro, E.; Wu, S.; and Romans, L., "Recent Advances in the Study of GPS Earth Surface Reflections from Orbiting Receivers, UNAVCO Community Meeting, December 1998.

143. Lowe, S.T.; LaBrecque, J.L.; Zuffada, C.; Romans, L.J.; Young, L.E.; and Hajj, G.A., "First Spaceborne Observation of an Earth-Reflected GPS Signal," submitted to J. Geophys. Res., January 2000.

144. Wu, S.C.; Meehan, T.K.; and Young, L.E., "The Potential Use of GPS Signals as Ocean Altimetry Observables," ION National Technical Meeting, Santa Monica, CA, January 1997.

145. Kaula, W.M., "Analysis of Satellite Observations for Longitudinal Variations of the Gravitational Field," Space Research, 2, pp. 360-372, 1961.

146. NRC, Satellite Gravity and the Geosphere, National Academy Press, Washington, DC, 1997.

147. Vetter, J.R.; Nerem, R.S.; Cefola, P.; and Hagar, H., "A Historical Survey of Earth Gravitational Models Used in Astrodynamics From Sputnik and Transit to GPS and TOPEX," Adv. Astronaut. Sci. 85, part II, 1994.

148. Mannucci, A.J.; Wilson, B.D.; Yuan, D.N.; Ho, C.M.; Lindqwister, U.J.; and Runge, T.F., "A Global Mapping Technique for GPS-derived Ionospheric Total Electron Content Measurements," Radio Sci. 33(3), pp. 565-583, 1998.

149. Hajj, G.A.; Ibañez-Meier, R.; Kursinski, E.R.; and Romans, L.J., "Imaging the Ionosphere with the Global Positioning System," Internat. J. of Imag. Sys. and Tech., 5, pp. 174-184, 1994.

150. Hajj, G.A.; Lee, L.C.; Pi, X.; Romans, L.J.; Schreiner, W.S.; Straus, P.R.; and Wang, C., "COSMIC Ionospheric Sensing and Space Weather," to appear in Terrestrial, Atmospheric and Oceanic Sciences, March 2000.

151. Yunck, T.P. and Melbourne, W.G., "Geoscience From GPS Tracking by Earth Satellites," IAG General Meeting, Edinburgh, Scotland, August 411, 1989, reprinted in Global Positioning System: An Overview, Y. Bock \& N. Leppard (eds.), Springer-Verlag, 1990.

152. Malla, R.P; Wu, S.C.; and Lichten, S.M., "Geocenter Location and Variations in Earth Orientation Using Global Positioning System Measurements," J. Geophys. Res._Solid Earth, 98 (B3), pp. 46114617, Mar 10, 1993.

153. Ceva, J., "Hughes Aircraft's Architectural Design of the Federal Aviation Administration Wide Area Augmentation System: An International System," 48th International Astronautical Congress, Turin, Italy, IAF-97-M.6.04, October 6-10, 1997.
154. Yunck, T.P.; Bertiger, W.I.; Lichten, S.M.; Mannucci, A.J.; Muellerschoen, R.J.; and Wu, S.C., A Robust and Efficient New Approach to Real Time Wide Area Differential GPS Navigation for Civil Aviation, JPL Report D-12584, April 1, 1995.

155. Yunck, T.P.; Bar-Sever, Y.E.; Bertiger, W.I.; Iijima, B.A.; Lichten, S.M.; Lindqwister, U.J.; Mannucci, A.J.; Muellerschoen, R.J.; Munson, T.N.; Romans, L.; and Wu, S.C., "A Prototype WADGPS System for Real Time Sub-Meter Positioning Worldwide," Proceedings of ION GPS 96, Kansas City, KS, September 1996.

156. Muellerschoen, R.J.; Bertiger, W.I.; and Lough, M.F., "Results of an Internet-Based Dual-Frequency Global Differential GPS System," ION Meeting, San Diego, CA, June 2000.

157. Muellerschoen, R.J.; Bar-Sever, Y.E.; Bertiger, W.I.; and Stowers, D.A., "NASA's Global DGPS for High-Precision Users," GPS World, Vol. 12, No. 1, pp. 14-20, January 2001.

158. Zhang, J. and Lachapelle, G., "Precise Estimation of Residual Tropospheric Delays Using a Regional GPS Network for RTK Applications," Journal of Geodesy, Springer Verlag, 2001 (in press).

159. Ware, R.H.; Fulker, D.W.; Stein, S.A.; Anderson, D.N.; Avery, S.K.; Clark, R.D.; Droegemeier, K.K.; Kuettner, J.P.; Minster, J.B.; and Sorooshian, S., "SuomiNet: A Real-Time National GPS Network for Atmospheric Research and Education," to appear in the Bulletin of the American Meteorological Society, Vol. 81, No. 4, pp. 677-694, April 2000. 